\title{
城市蓝绿基础设施降温效应研究综述
}

\author{
苏王新 ${ }^{1}$, 常 青 $^{1, *}$, 刘 篟 ${ }^{2}$, 张刘宽 ${ }^{1}$ \\ 1 中国农业大学园艺学院, 北京 100193 \\ 2 上海钧正网络科技有限公司，上海 201199
}

\begin{abstract}
摘要:蓝绿基础设施对于调节城市气候、应对未来气候变化和增强城市韧性极为重要。采用文献分析法系统梳理城市蓝绿基础 设施降温效应研究特点, 结合气候区特征从景观、类型和群落斑块尺度上分析蓝绿基础设施降温效应及其关键影响因素,并尝 试运用 Meta 分析统计城市蓝绿基础设施降温效应的定量指标,最终面向规划设计实践需求提出未来城市蓝绿基础设施降温效 应研究的三大挑战: (1) 衔接城市和街区尺度上蓝绿基础设施降温效应研究,笁选关键的蓝绿基础设施热缓解参数,指导城市 绿地系统规划定量指标的设定; (2)整合水平与垂直的多维度蓝绿基础设施降温效应研究,结合街区特征确定降温阈值, 以指 导控制性详细规划中的蓝绿基础设施布局; (3) 探究影响不同单体植物降温效率的核心要素,筛选最优降温植物群落配置, 指 导场地尺度上植物降温的种植设计。
\end{abstract}

关键词:蓝绿基础设施; 缓解热岛效应; Meta 分析;规划设计;城市韧性

\section{Cooling effect of urban green and blue infrastructure: a systematic review of empirical evidence}

\author{
SU Wangxin ${ }^{1}$, CHANG Qing ${ }^{1, *}$, LIU Xiao ${ }^{2}$, ZHANG Liukuan ${ }^{1}$ \\ 1 Department of Ornamental Horticulture and Landscape Architecture, China Agricultural University, Beijing 100193, China \\ 2 Shanghai Jun Zheng Network Technology Co. Ltd., Shanghai 201199, China
}

\begin{abstract}
Urban green and blue infrastructure (GBI) plays an extremely important role in regulating urban climate and assisting cities to cope with future climate change and enhance urban resilience. This paper presents a comprehensive review of urban green and blue infrastructure researches on cooling effect trends and hotspots, and the distribution of cooling effect studies in different climatic zones. Most studies focused on surface types and configurations, urban parks and water bodies, roof greening ( building energy conservation), ecological benefits, thermal comfort, plant communities, etc. through remote sensing imagery, ground measurement, and comprehensive simulation. Most studies were influenced by the research field (perspective) and the research scale dependence of urban green and blue infrastructure cooling effect was extremely obvious. Based on the Köppen climate classification, the research methods, indicators and key issues are different at scale level. Through the analysis of cooling effect of green and blue infrastructure and its influencing factors from the landscape, patch (corridor) and community scale, we found that the cooling effect was mainly affected by the proportion of ecological land, landscape pattern (landscape scale); patch area, underlying surface type (patch scale); and plant configuration, single plant ( community scale), etc. Meta-analysis was used to synthesize data on the cooling effect of parks and the results showed that, on average, a park was $1.39{ }^{\circ} \mathrm{C}$ cooler in temperate climate zone and $3.12{ }^{\circ} \mathrm{C}$ cooler in continental climate zone. On this basis, this paper summarizes three challenges in the future research on the cooling effect of urban green and
\end{abstract}

基金项目:国家自然科学基金面上项目(41771204)

收稿日期:2019-03-29; 修订日期:2020-09-14

*通讯作者 Corresponding author.E-mail: changqing@ cau.edu.cn 
blue infrastructure based on the practical needs of urban planning and design: (1) The cooling effect of green and blue infrastructure on city and block scale should be connected to determine key heat mitigation parameters of GBI planning and design, and furthermore provide quantitative indicators for urban green space system planning; (2) The multi-dimensional of the horizontal distribution and vertical transmission spaces on the cooling effect of green and blue infrastructure studies should be integrated, and the characteristics of blocks should be combined to determine the cooling threshold for guiding and optimizing the distribution of GBI in regulatory detailed planning; (3) The pivotal indicators and thresholds of each plant or plant community configurations in heat mitigation should be determined for guiding the plant cooling design on site scale. Further multi-scale and multi-dimensional research is necessary in order to efficiently guide the planning and design of urban green and blue infrastructure in urban growth strategies, and warrants greater consideration in urban planning policy to mitigate the adverse effects of the urban heat islands and enhance climate resilience.

Key Words: green and blue infrastructure ( GBI); heat island mitigation; Meta-analysis; planning and design; urban resilience

高度城市化造成的城市及周围绿地损失和退化已对生态系统健康与人类福祉产生不利影响 ${ }^{[1]}$ 。在全球 范围内, 由于土地利用与覆被类型变化和强烈的人类活动导致城市地表热力学性质改变 ${ }^{[2]}$ 、热岛效应( UHI, Urban Heat Island ${ }^{[3-4]}$ 和极端热事件 (EHE, Extreme High Temperature Events) 导致的人类健康 ${ }^{[5-6]}$ 问题已引起 全球关注。世界各国政府和研究人员不断探索各种措施以增强应对全球气候变化、UHI 和 EHE 等复合效应 的城市适应能力 ${ }^{[7-8]}$ 。城市蓝绿基础设施 (GBI, Green and Blue Infrastructure) 是由自然、半自然和人工绿色植 被、水体为一体的生物栖息地网络体系 ${ }^{[1,9-11]}$, 在调节城市气候和协助城市应对未来气候变化中扮演着极为重 要的角色 ${ }^{[12-13]}$ 。城市蓝绿基础设施降温效应已成为国内外热岛效应减缓与适应的科学前沿与实践热 点 ${ }^{[14-15]}$ 。积极规划、建设和管理多种类型的蓝绿基础设施, 有助于改变城市局地能量平衡、缓解城市热岛对 人类生产、生活产生的影响 ${ }^{[16-17]}$ 。

本文通过文献分析总结国内外 GBI 降温效应研究概况及在不同气候区的分布特征, 系统梳理不同气候 区在景观、类型和群落斑块尺度上的 GBI 降温效应、影响因素及通用的研究方法,探讨 GBI 降温效应对不同 层次规划设计实践的启示, 并据此提出未来 GBI 降温效应研究的主要议题和研究展望, 以期为深人城市蓝绿 基础设施降温效应研究、更好地指导适应性规划设计提供借鉴和参考。

\section{1 国内外城市蓝绿基础设施降温效应研究概况}

在 Web of science 核心数据库和 CNKI 数据库中, 本文分别以“Green and Blue Infrastructure”、“Heat Island Mitigation” “Cooling Effect” 以及“绿地”、“水体”、“缓解热岛”、“降温”为主题词进行检索,截至 2018 年 12 月,检索到外文期刊文献 929 篇, 中文核心期刊文献 267 篇, 2000 年以前年发文量均小于 6 篇, 之后呈显著上 升趋势; 主要涉及生态环境科学 $(36 \%)$ 、建筑科学 $(24 \%)$ 、大气科学 $(14 \%) 、$ 城市学 $(12 \%)$ 、林学 $(8 \%)$ 和遥感 (6\%) 等领域(图 1)。

从主题词出现次数来看, 外文文献研究热点包括屋顶绿化 (建筑节能)、降温影响因素、环境变化模拟、降 温效益、热舒适性、适应减缓策略和城市规划等; 中文研究热点则聚焦于降温增湿、绿地特性(面积、结构、类 型)、立体绿化、微气候、植物群落等方面 (图 2)。受研究领域 (视角) 的影响, 蓝绿基础设施降温效应研究内 容和方法具有明显尺度依赖性 ${ }^{[15,18]}$ 。生态环境学和城市气象学多关注景观甚至区域尺度上的蓝绿基础设施 景观格局对城市热岛的缓解效应, 采用 RS 与 GIS 技术、通过卫星遥感影像获取城市下垫面特性和地表温度,

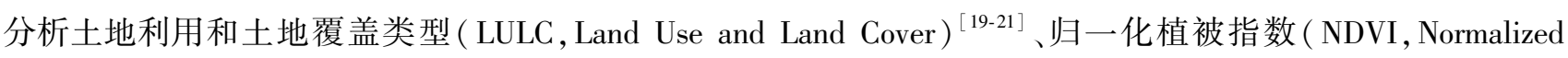
Difference Vegetation Index $)^{[14,22-20]}$ 、植被覆盖度 (FV, Vegetation Fraction $)^{[24-25]}$ 、改进的归一化差异水体指数 (MNDWI, Modified Normalized Difference Water Index ${ }^{[26]}$ 等与地表温度之间的关系; 受大气辐射条件影响, 地 


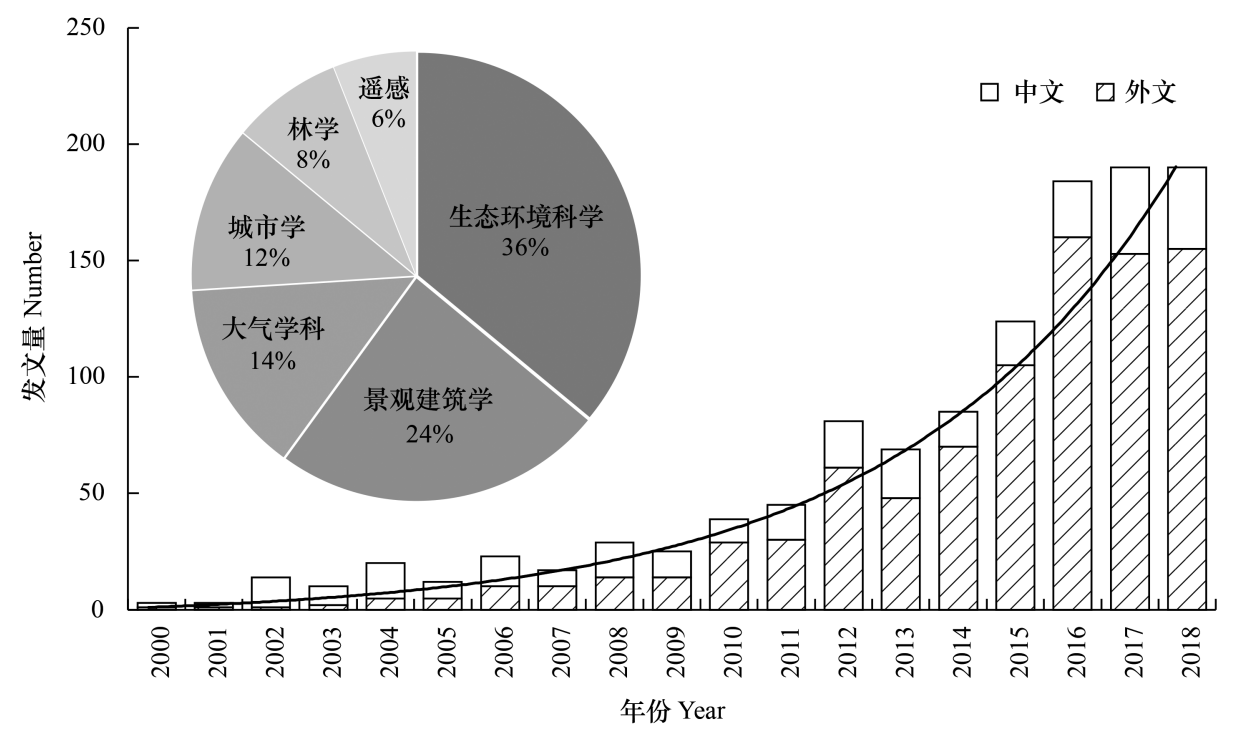

图 1 国内外蓝绿基础设施降温效应研究发展趋势

Fig.1 The research trend in cooling effect of green and blue infrastructure

表温度反演方法及精度对景观尺度上 GBI 降温效应研究造成一定限制。建筑学采用实测法和数值模拟法研 究类型和斑块尺度 GBI 的降温效应(如城市公园与绿地、立体绿化、植物群落和植株个体); 其中实测法主要 基于实地观测或气象站监测数据; 数值模拟法主要基于 ENVI-met ${ }^{[27-28]} 、$ Phoenics $^{[29]} 、 \mathrm{CFD}$ (计算流体动力学, Computational Fluid Dynamics) ${ }^{[30]}$ 、STEVE( Screening Tool for Estate Environment Evaluation, 建筑环境气温预测 工具) ${ }^{[31]}$ 、SPOTE (Simulation Platform for Outdoor Thermal Environment, 室外热环境模拟软件平台) ${ }^{[32]}$ 等模型 经参数修正后模拟局部微气候, 分析不同绿地类型与植物群落特征因素对温度的影响。
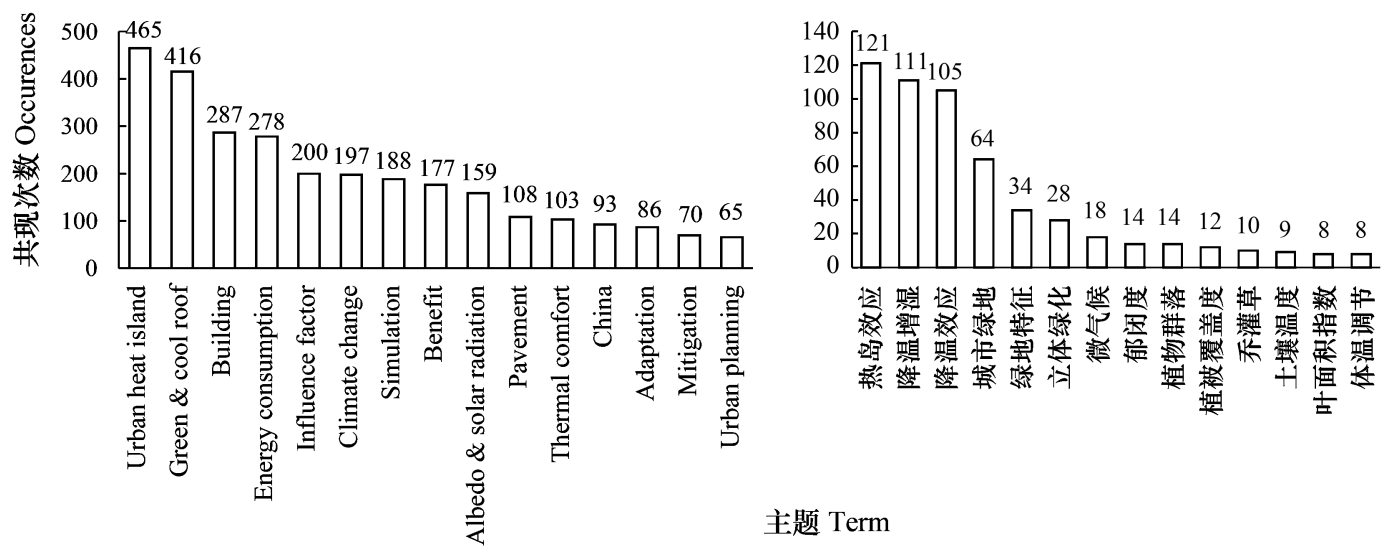

主题 Term

图 2 国内外蓝绿基础设施降温效应研究文献词频排序

Fig.2 The word frequency ranking of published articles concerning the cooling effect of green and blue infrastructure

鉴于不同气候区对城市热岛效应和蓝绿基础设施降温效应存在强烈的影响 ${ }^{[33-34]}$, 本文参考柯本气候分 类 (Köppen climate classification $)^{[35]}$ 对收集的主要文献进行气候分区数量统计,结果显示除极地带 $(\mathrm{E}$ 类) 外, 其他 4 个气候区均有蓝绿基础设施降温效应研究 (图 3 )。其中, 位于温暖带 ( C 类) 的相关研究最多 $(50.94 \%)$, 占比分别为 $\mathrm{Cfa}(22.63 \%) 、 \mathrm{Cwa}(9.43 \%) 、 \mathrm{Cfb}(9.43 \%) 、 \mathrm{Csa}(7.55 \%)$ 和 $\mathrm{Csb}(1.89 \%)$ 的; 其次为内陆 带 ( D 类) ( $28.3 \%$ ) 和热带 ( A 类) ( $28.3 \%$ ), 位于干旱带 (B 类) 气候区的相关研究最少 $(5.66 \%)$ 。有鉴于此, 
下文主要基于气候分区从景观、类型和斑块群落尺度深人分析蓝绿基础设施降温效应及其影响因素,并探讨 其对蓝绿基础设施规划设计实践的启示。

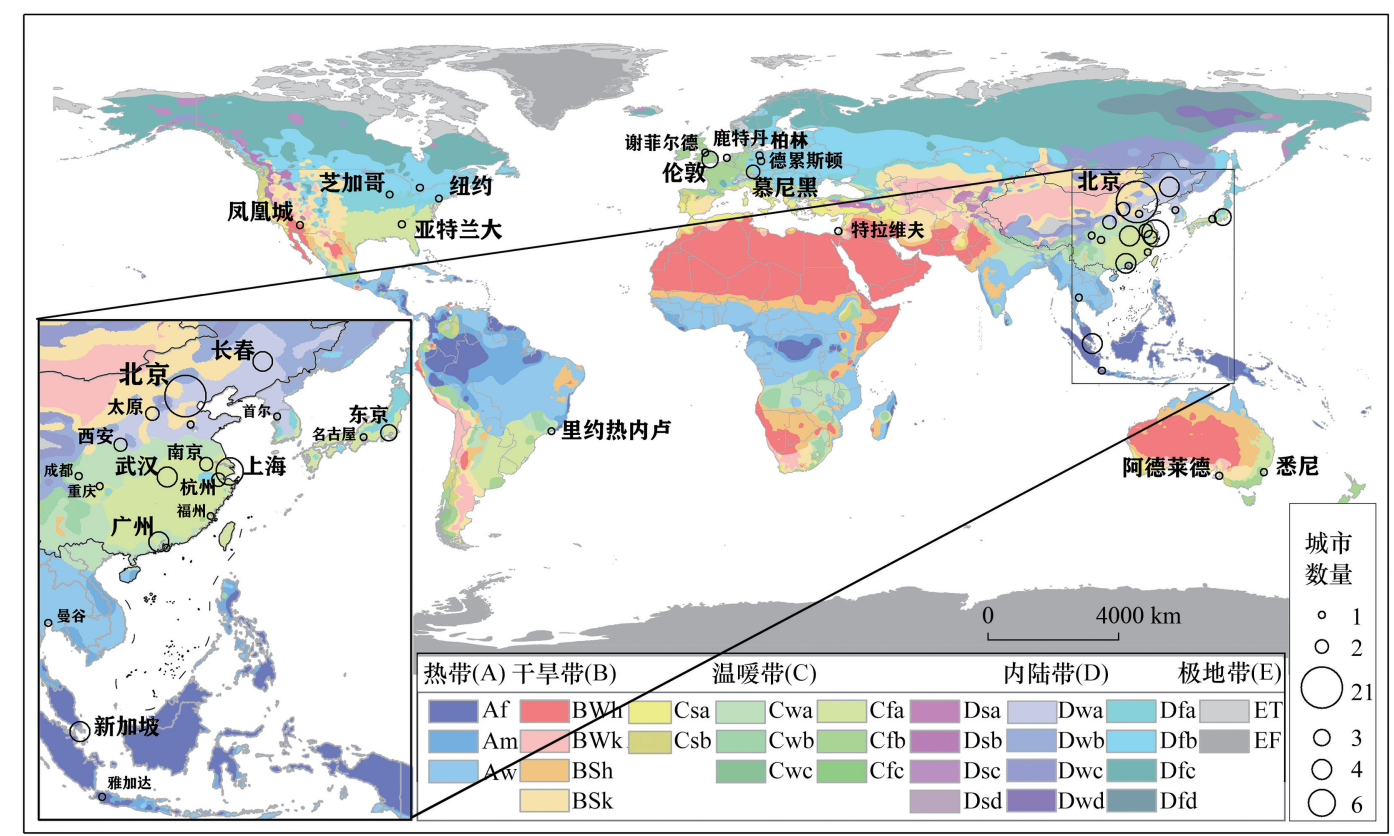

图 3 不同柯本气候分区中的主要研究分布图

Fig.3 The distributions of main studies in different Köppen climate classifications zones

本研究主要涉及的柯本气候分区包括: 热带 (A 类) : Af: 热带雨林气候, Tropical rainforest climate; Am: 热带季风气候, Tropical monsoon climate; Aw : 热带干湿季气候,Tropical wet and dry or savanna climate。干旱带(B 类) : BWh:热带沙漠气候, Hot desert climate; BSh:热带草原气 候,Hot semi-arid climate; BSk: 温带草原气候,Cold semi-arid climate。暖温带 (C 类): Cfa: 亚热带季风气候, Humid subtropical climate; Cwa:亚 热带季风气候(热型), Monsoon-influenced humid subtropical climate; Cfb: 温带海洋性气候,Temperate oceanic climate; Csa: 地中海气候(热型), Hot-summer Mediterranean climate; Csb: 地中海气候(暖型), Warm-summer Mediterranean climate。内陆带(D 类): Dfa: 大陆湿润气候(热型), Hot-summer humid continental climate; Dwa: 大陆冬旱气候(热型), Monsoon-influenced hot-summer humid continental climate; Dfb: 大陆湿润气候 (暖型),Warm-summer humid continental climate

\section{2 不同尺度下蓝绿基础设施的降温效应及其影响因素}

\section{1 景观尺度}

景观尺度上,城市蓝绿基础设施是与建设用地空间共轭的有机生态网络; 其降温效应研究侧重于城市蓝 绿基础设施及建设用地的覆被性状、类型结构和空间构型关系对地表温度的影响机制 (表 1),且多以“瞬时” 状态下的关系研究为主。城市扩张中绿地缓解热岛的作用及价值在定量评估 ${ }^{[41-42]}$ 和模型估算 ${ }^{[43]}$ 等方面也有 涉及。

城市蓝绿基础设施及建设用地类型结构和空间布局形态均会影响地表温度 ${ }^{[18,39,44]}$,进而 GBI 表现出不 同的降温效应。在景观组成方面,城市建设用地内 GBI 的面积、组成比例和分布位置等特征是影响其降温效 应的主要因素。许多研究表明,植被覆盖度越高其降温效应越显著 ${ }^{[25]}$,增加绿地面积有助于缓解城市热岛效 应 ${ }^{[19,36,40]}$, 面积相同内部组成不同的绿地其温度调节服务具有一定差异 ${ }^{[36]}$ 。UHI 与城市用地占比呈显著正 相关, 与林地占比呈显著负相关; 草地、耕地、水体和裸地占比与 UHI 之间因城市用地特征不同而存在较大的 差异 ${ }^{[21,39,45]}$ 。在城乡梯度上平均 LST 与不透水面密度 (正) 和绿地密度 (负) 之间存在显著的强相关性, 且呈 现出典型的 UHI 剖面 ${ }^{[40]}$ 。随着城市化进程的推进,郊区 GBI 减少不透水用地增加,出现热岛规模扩大, 而市 中心区热岛效应有所下降 ${ }^{[19]}$ 。不同气候区, 缓解 UHI 的景观组成也存在较大差异, 且绿地和水体的降温效应 
不尽相同 ${ }^{[2,21,26]}$ 。济南市 (BSk) 最能缓解 UHI 的为林地和耕地、武汉市 (Cfa) 为水体、重庆市 (Cfa) 为 林地 ${ }^{[21]}$ 。

\section{表 1 景观尺度城市蓝绿基础设施降温效应及其影响因素}

Table 1 Factors influencing the cooling effect of urban green space in landscape scale

\begin{tabular}{|c|c|c|c|}
\hline \multirow{2}{*}{$\begin{array}{l}\text { 气候区 } \\
\text { Climate zone }\end{array}$} & \multicolumn{3}{|c|}{$\begin{array}{l}\text { 蓝绿基础设施要素特征及其与 LST 定量关系 } \\
\text { Features of green-blue infrastructure elements and their quantitative relationship with LST }\end{array}$} \\
\hline & 景观组成 Composition & 景观配置 Configuration & 覆被性状 Cover \\
\hline $\begin{array}{l}\mathrm{A} \text { 类 } / \mathrm{B} \text { 类 } / \mathrm{C} \text { 类 } / \mathrm{D} \text { 类 } \\
\text { 气候区 } \\
\mathrm{A} / \mathrm{B} / \mathrm{C} / \mathrm{D} \text { climate types }\end{array}$ & $\begin{array}{l}\text { 生态用地覆盖率、生态用地占比、空 } \\
\text { 间组成变化、植被覆盖度、PIM、PBU、 } \\
\text { PWO 、PFA、PWA、PTR、PV 等 }\end{array}$ & $\begin{array}{l}\text { LSI、LFI、连通性、复杂性、WA、DIST、 } \\
\text { PB、PD、SDPA、SDSI、LPI、IJI 、 } \\
\text { SHDI 等 }\end{array}$ & $\begin{array}{l}\mathrm{LAI} 、 N D V I 、 F V 、 M N D W 、 N D W I 、 \\
\mathrm{NDBaI} 、 N D B I \text { 等 }\end{array}$ \\
\hline $\begin{array}{l}\text { 内陆带 (D 类) : } \\
\text { Dfa/Dwa/Dfb } \\
\text { Continental ( D types) }\end{array}$ & $\begin{array}{l}\text { - 生态用地覆盖率 }>70 \%\left(25 \mathrm{~km}^{2}\right) \text {, } \\
\text { 降温效率相对明显; 生态用地占比 } \\
(\mathrm{PC}=0.614)^{[19]} \text { 。 } \\
\text { - 绿地扩张区 LST 下降 }(-1.11- \\
\left.0.67^{\circ} \mathrm{C}\right) \text {; 损失地区 LST 上升 }(1.64- \\
\left.2.21^{\circ} \mathrm{C}\right)^{[36]} \text { 。 } \\
\text { - 植被覆 盖度每平方公里 } 70 \% \text { - } \\
80 \% \text { 的地区, 降温显著 }{ }^{[24]}\end{array}$ & $\begin{array}{l}\text { - 绿地 LST 与 } \mathrm{LSI}\left(\mathrm{PC}=0.59, R^{2}=\right. \\
0.35) 、 \mathrm{LFI}\left(\mathrm{PC}=0.51, R^{2}=0.26\right)^{[19]} \text { 。 } \\
\text { - 水体 UCI 强度与 WA、PBU 呈正相 } \\
\text { 关, 与 LSI、DIST 呈负相关 }{ }^{[37]}\end{array}$ & $\begin{array}{l}\text { - } \mathrm{LAI}\left(R^{2}=0.62\right), \mathrm{LAI} \text { 每增加 } \\
\text { 一个单位, 地表温度下降 } \\
1.2^{\circ} \mathrm{C}^{[38]}\end{array}$ \\
\hline $\begin{array}{l}\text { 温暖带 }(\mathrm{C} \text { 类) }: \mathrm{Cfa} / \mathrm{Cwa} \\
\text { Temperature }(\mathrm{C} \text { types })\end{array}$ & $\begin{array}{l}\text { - } \mathrm{PBU}\left(R^{2}=0.42\right) 、 \mathrm{PWO}\left(R^{2}=\right. \\
-0.48)[21] \text { 。 } \\
\text { - 上海市植被较水体的降温作 } \\
\text { 用大 }{ }^{[26]}\end{array}$ & $\begin{array}{l}\text { - 绿地 PD/SDPA/LPI }\left(R^{2}=-0.42,-\right. \\
0.40,-0.41) 、 \mathrm{SDSI} / \mathrm{IJI} / \mathrm{SHDI}\left(R^{2}=0 .\right. \\
30,0.45,0.40)^{[39]}\end{array}$ & $\begin{array}{l}\text { - NDVI }, \text { MNDWI }\left(R^{2}=0.96 \text {, }\right. \\
0.61)^{[26]}\end{array}$ \\
\hline $\begin{array}{l}\text { 热带 }(\mathrm{A} \text { 类) : Aw } \\
\text { Tropical ( A types })\end{array}$ & $\begin{array}{l}\text { - 不透水表面比绿色空间的平均 } \\
\text { LST 高约 } 3^{\circ} \mathrm{C}^{[40]}\end{array}$ & - & - \\
\hline $\begin{array}{l}\text { 干旱带 ( } \mathrm{B} \text { 类) : Bsh/Bsk } \\
\text { Arid (B types) }\end{array}$ & $\begin{array}{l}\text { - } \mathrm{PBU}\left(R^{2}=0.42\right) 、 \operatorname{PWO}\left(R^{2}=\right. \\
-0.48)^{[21]}\end{array}$ & - & - \\
\hline
\end{tabular}

括号内为相关系数, $R^{2}$ 为不同指标与地表温度的相关性系数; PC 皮尔森相关系数; LST: 地表温度 Land surface temperature; UCI: 城市冷岛 Urban cooling island; PBU : 建筑用地占比 Percent cover of buildings; PWO : 林地占比 Percent cover of woodland; PFA: 耕地占比 Percent cover of finetextured vegetation;PWA: 水体占比 Percent cover of water areas; PTR: 交通用地占比 Percent cover of transportation; PV : 绿地占比 Percent cover of vegetation;PIM: 不透水占比 Percent cover of impervious; LSI:形状指数 the shape index of ecological land; LFI: 破碎度指数 the fragmentation index of ecological land;DIST:距离指数 the water body location in reference to a defined city center; PD: 斑块密度 Patch Density; SDPA: 标准化面积指数 Standard Deviation of Patch Area;SDSI: 标准化形状指数 Standard Deviation of Shape Index; LPI: 最大斑块指数 Largest Patch Index; IJI: 散布与并列指 数 Interspersion Juxtaposition Index; SHDI: 多样性指数 Shannon's Diversity Index; NDWI: 标准化差异水指数 Normalized Difference Water Index; NDBaI: 归一化差异裸度指数 Normalized Difference Bareness Index; NDBI : 归一化差异累积指数 Normalized Difference Build-up Index

在景观配置方面,GBI 的景观组成、空间形态、空间位置及其空间临接关系对热环境均存在较大影响。绿 地形态的相对简化和相互联系的增强可以显著降低热环境影响,且连通性对降温效应产生的影响在夏季更显 著 ${ }^{[19,39,46]}$ 。湖泊湿地降温面积达到临界值后,多斑块离散型布局对城市整体降温效应更显著 ${ }^{[46]}$,增加水域的 连通性可以减缓区域 LST 的变化 ${ }^{[47]}$ 。不透水面和绿地斑块的大小、形状复杂度和聚集度与平均 LST 也有显 著关系,但聚集性的相关性最强 ${ }^{[40]}$ 。

NDVI、叶面积指数( LAI, Leaf area index)、不透水指数( ISA, Impervious surface area)等覆被性状是城市蓝 绿基础设施植被覆盖程度、植物群落生长和土壤等综合状况的反映。许多研究表明, NDVI、FV、LAI 与 LST 之

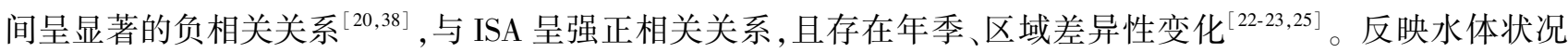
的 MNDWI 同地表温度呈显著线性关系 ${ }^{[26]}$; 水体城市冷岛 (UCI) 强度与水体面积 (WA)、周围建筑比例 (PB) 呈正相关, 与景观形状指数 (LSI) 、位置 (DIST) 呈负相关; 水体 UCI 效率与 PB 呈正相关, 与 WA、LSI、DIST 呈 负相关 ${ }^{[37]}$ 。

\section{2 类型尺度}

根据城市蓝绿基础设施网络构成及我国绿地分类标准,本文主要从节点绿地类型 (公园绿地、附属绿地、 
建筑立体绿化和湖泊湿地) 和廊道绿地类型 (河流、绿道)两个层面分析城市蓝绿基础设施的降温效应和影响

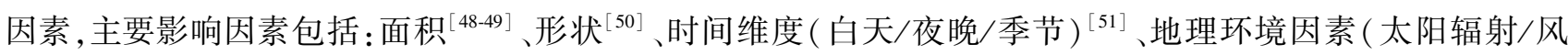
向/风速/地形/高程/海拔/气候 $)^{[52]}$ 等。

(1) 节点绿地类型

公园绿地是城市蓝绿基础设施降温效应研究的集大成者(表 2)。许多研究表明,公园绿地降温效应取决 于公园绿地面积 ${ }^{[23,49]}$ 、水体面积比例 ${ }^{[53,56]}$ 、与外围建设用地的空间邻接关系 ${ }^{[58,61]}$ 及其所在气候区季节辐射 条件 ${ }^{[50]}$ 等, 且存在阈值 ${ }^{[16,62]}$ 。例如伦敦市 $(\mathrm{Cfb}) 1.11 \mathrm{~km}^{2}$ 公园绿地夜间降温距离为 $20-440 \mathrm{~m}{ }^{[58]}$, 日本东京 市 $(\mathrm{Cfa}) 0.6 \mathrm{~km}^{2}$ 公园在中午的气候影响可扩展到其边界以外 $1000 \mathrm{~m}$ 降温 $1.5^{\circ} \mathrm{C}^{[63]}$, 广州市 $(\mathrm{Cwa})$ 公园降温最 大降温距离为 $418 \mathrm{~m}$, 降温 $1-2^{\circ} \mathrm{C}{ }^{[56]}$ 。公园降温强度在夏季大于秋季, 且与风速呈较强的正相关关 系 ${ }^{[59,60,63]}$; 优化公园形状和森林结构能够增加降温强度 ${ }^{[50,54]}$; 且随着公园内部绿地、树冠和草地面积的增加 降温距离呈线性增加 ${ }^{[57]}$, 随距离建筑物和水体的距离增加呈非线性递减 ${ }^{[55]}$ 。有研究表明, UCI 可能受其空 间位置的影响,但不受其海拔高度的影响 ${ }^{[55]}$ 。气候越热越干燥的地区,植被对城市温度的影响就越大; 当表 面被植被覆盖时, 表面接收的太阳辐射量越大, 其温度下降幅度就越大 ${ }^{[52]}$ 。

表 2 类型尺度 (公园绿地) 城市蓝绿基础设施降温效应影响因素

Table 2 Factors influencing the cooling effect of urban green space in class scale (Green Park)

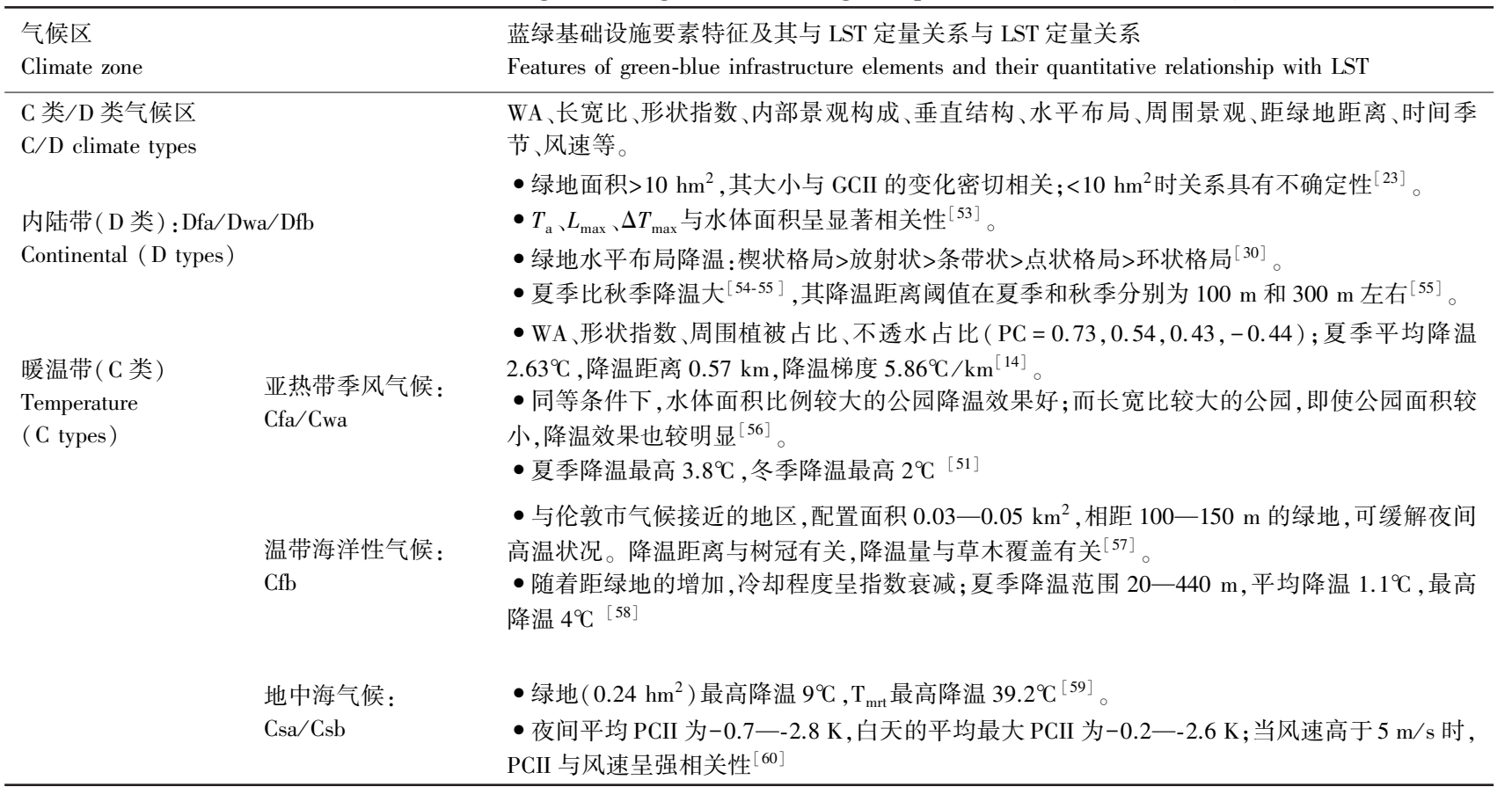

GCII: 绿地冷岛强度, Green cool island index; PCII : 公园冷岛强度指数, Park cool island index; $T_{\mathrm{a}}$ : 地表温度, Surface temperature; $L_{\max }$ : 降温最大 范围, Sphere of influence on the surrounding environment; $\Delta T_{\text {max }}$ : 降温幅度, Maximum cooling range

与公园绿地不同,附属绿地 (表 3) 由于位于建设用地内部,其降温效应研究除自身状况如绿化覆盖率、绿 化最大斑块面积、乔木面积比例、绿化斑块的破碎度 ${ }^{[28,66,72]}$ 等以外,更加关注绿地与建设用地的相互关系,如 建筑高度、建筑密度、容积率、风向等 ${ }^{[28,67]}$ 。有研究表明, 居住区平均温度与乔木面积比例、绿化覆盖率、绿化 最大斑块面积呈正相关, 与绿化斑块的破碎度呈负相关 ${ }^{[66]}$; 其内不透水表面和树冠的占比可解释 $91 \%$ 的气温 变化 ${ }^{[64]}$; 夏季高温季节以沥青路面的地表温度为对照,其内不同植被类型的降温效应林地 $>$ 水体 $>$ 草地 $>$ 裸 地 ${ }^{[27-28,64]}$; 绿地率相同时, 乔木降温效果优于草地 $7^{\circ} \mathrm{C}^{[28]}$ 。不同建筑布局形式的居住用地绿地降温效应存在 较明显差异, 如上海市低植被覆盖度的低层至中层建筑区温度高于高植被覆盖度的高层建筑区 ${ }^{[20]}$; 行列式独 栋建筑和多层与中、高层建筑用地, 最有效调节温度的乔木覆盖率 $(25 \%-30 \%)$ 要高于密集型行列式布局的 建筑用地 $(15 \%)^{[28]}$; 建筑密度相似时高度越高, 遮阴越多,场地平均气温越低 ${ }^{[28]}$ 。 
立体绿化 (表 3 ) 是城市建筑本体降温的主要手段,其降温效应研究主要集中于垂直绿化和屋顶绿化降低 环境温度、减弱周围热压力、减少建筑能耗和提高人类福祉等方面 ${ }^{[66,70,73-74]}$ 。多数研究显示, 立体绿化降温效 果在夏季最明显, 且晴天降温明显高于阴天 ${ }^{[52,69,74]}$ 。立体绿化降温效应除了受城市峡谷几何状态的影响 外 ${ }^{52]}$, 还受到立体绿化工程技术参数的影响, 主要包括屋板坡度、种植介质深度、植物叶面的反射率和蒸散 率、垂直结构以及植物活性等 ${ }^{[31,65]}$ 。屋顶的平均日降温高于峡谷内部的平均日降温 ${ }^{[52]}$; 侧墙有垂直植被种植 的建筑区,随着街区天空可视因子的增大,夏季温度下降和能量节约趋于增加 ${ }^{[68]}$ 。不同气候区立体绿化降温效 应的定量特征重点是背景的相对湿度,其与植被的蒸散量直接相关 ${ }^{[73]}$, 因而在不同的城市降温差异性较大。

\section{表 3 类型尺度 (附属绿地 \& 垂直绿化) 城市蓝绿基础设施降温效应影响因素}

Table 3 Factors influencing the cooling effect of urban green space in class scale (Affiliated green space \& Vertical greening)

\begin{tabular}{|c|c|}
\hline $\begin{array}{l}\text { 气候区 } \\
\text { Climate zone }\end{array}$ & $\begin{array}{l}\text { 蓝绿基础设施要素特征及其与 LST 定量关系 } \\
\text { Features of green-blue infrastructure elements and their quantitative relationship with LST }\end{array}$ \\
\hline $\begin{array}{l}\mathrm{A} \text { 类 } / \mathrm{B} \text { 类/C 类 } / \mathrm{D} \text { 类气候区 } \\
\mathrm{A} / \mathrm{B} / \mathrm{C} / \mathrm{D} \text { climate types }\end{array}$ & $\begin{array}{l}\text { 下垫面类型、绿化覆盖率、冠层覆盖度、大斑块面积、破碎度、垂直结构、天气风向、天空可视因子、时间季 } \\
\text { 节; 立体绿化、植物生物活性、反照率、乔木面积比例、蒸腾率、LAI、度等 }\end{array}$ \\
\hline $\begin{array}{l}\text { 内陆带 }(\mathrm{D} \text { 类 }): \mathrm{Dfa} / \mathrm{Dwa} / \mathrm{Dfb} \\
\text { Continental ( D types) }\end{array}$ & $\begin{array}{l}\text { - 凌晨 } 2 \text { 点,市区不透水和树冠占比可解释 } 68 \% \text { 的气温变化, 极端高温事件时可解释 } 91 \% \text {; 下午 } 4 \text { 点重要 } \\
\text { 的解释变量是到工地的距离 }{ }^{[64]} \text { 。 } \\
\text { - 纽约绿色屋顶上植被最多和最少的区域间平均温度差为 } 2^{\circ} \mathrm{C} \text {; 植物的生物活性和表面反照率对降温起 } \\
\text { 着至关重要的作用 }[65]\end{array}$ \\
\hline $\begin{array}{l}\text { 温暖带 }(\mathrm{C} \text { 类 }): \mathrm{Cfa} / \mathrm{Cwa} / \mathrm{Cfb} \\
\text { Temperature }(\mathrm{C} \text { types })\end{array}$ & $\begin{array}{l}\text { - 降温效果取决于绿地斑块乔木盖度大小, 大乔木>草坪 }\left(2.2^{\circ} \mathrm{C}\right) \text {, 立体绿化可降低室温 } 0.5-5^{\circ} \mathrm{C}{ }^{[28,66]} \text { 。 } \\
\text { - 通向稻田的街道,顺风方向降温距离约为 } 150 \mathrm{~m} \text {, 垂直于风向的街道无温差 }{ }^{[67]} \text { 。 } \\
\text { - 雨蓬近地面夏季降温 } 0.2-1.2^{\circ} \mathrm{C} \text {, 节能 } 4 \%-40 \%{ }^{[68]} \text { 。 } \\
\text { - 绿墙晴天降温 } 6.1^{\circ} \mathrm{C} \text {; 多云天降温 } 4.0^{\circ} \mathrm{C} \text { 。降温功能主要取决于植物的强度和方向。常春藤 ( } 10 \mathrm{~cm} \text { 厚) } \\
\text { 绿墙, 平均降温 } 2.5^{\circ} \mathrm{C}^{[69]}\end{array}$ \\
\hline $\begin{array}{l}\text { 热带 }(\mathrm{A} \text { 类 }): \mathrm{Aw} / \mathrm{Af} / \mathrm{Am} / \mathrm{Bwh} \\
\text { Tropical }(\text { A types })\end{array}$ & $\begin{array}{l}\text { - 绿色屋顶可降低建筑能耗 } 3 \% \text {; } \mathrm{LAI} \text { 增加导致白天行人水平的空气温降温提高 } 0.4^{\circ} \mathrm{C}^{[70]} \text { 。 } \\
\text { - 新加坡垂直绿化夏季平均降温 } 8.4^{\circ} \mathrm{C}^{[71]} \text { 。 } \\
\text {-气候越热越干燥,植被对城市温度的影响就越大; 当表面被植被覆盖时, 表面接收的太阳辐射量越大, } \\
\text { 其降温幅度就越大 } \text {, }^{52]}\end{array}$ \\
\hline $\begin{array}{l}\text { 干早带 (B 类) : Bsk/Bsh } \\
\text { Arid (B types) }\end{array}$ & $\begin{array}{l}\text { - 冠层覆盖度每增加 } 1 \% \text {, 温度下降 } 0.14^{\circ} \mathrm{C}^{[72]} \text {; 树冠覆盖率从 } 10 \% \text { 增加到 } 25 \% \text {, 可使降温提高到 } 2.0^{\circ} \mathrm{C} \text {; 凉 } \\
\text { 蓬可降温 } 0.3^{\circ} \mathrm{C} \text { [72] }\end{array}$ \\
\hline
\end{tabular}

水体湿地降温效果 (表 4) 主要受其自身固有属性、蒸散比率和周边环境的影 ${ }^{\text {向 }}{ }^{[37,79-80]}$; 其中水体的面积、 形状 (LSI) 和位置是影响城市区域 UCI 强度的重要指标 ${ }^{[76,78,81]}$ 。有研究表明, 水体的降温强度和降温效率与 水体面积、周围建筑比例呈正相关 ${ }^{[75,78,81]}$; 面状水域景观的热环境效应要强于线状河流景观,且面状水域景 观对热环境影响随着与热岛中心距离的增加而明显降低 ${ }^{[76,81]}$; 夏季可通过优化水体边缘或缓冲区内绿色基 础设施和通风廊道产生协同降温效应 ${ }^{[77]}$ 。特殊的,在鹿特丹市 $(C f b)$ 的研究表明,水的高热容量抑制了水上 生物圈的年循环,在夜间和季节转换后水温仍然相对较高, 因而城市湖泊增加而不是减少城市热岛效应 ${ }^{[79]}$ 。

表 4 类型尺度 (水体湿地) 城市蓝绿基础设施降温效应影响因素

Table 4 Factors influencing the cooling effect of urban green space in class scale (Water \& wetlands)

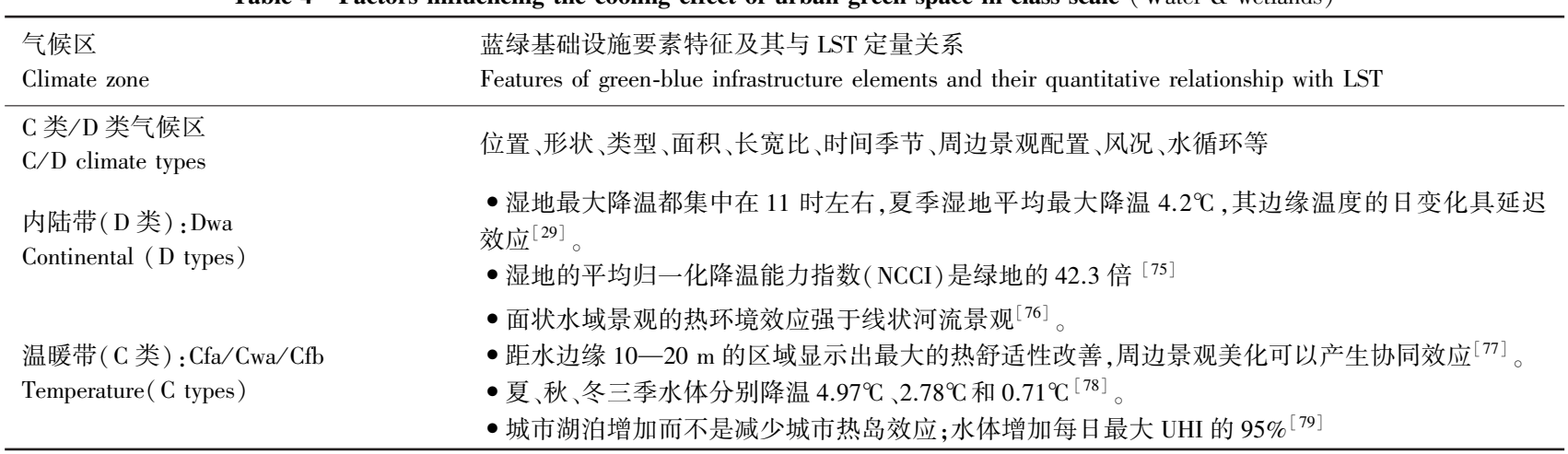

NCCI : 归一化降温能力指数, Normalized cooling capability index 
(2) 廊道绿地类型

城市蓝绿廊道主要通过物理作用力促进地区通风、传输新鲜空气、缓解空气污染、切割城市热场,消除热 岛的规模效应和叠加效应。其降温效应除受自身宽度影响之外,还受周边城市形态、景观配置、空气温度、水 文连通性的影响，且与河流水温、流经区域、人射太阳辐射、风速和相对湿度之间也存在季节性的依赖关 系 ${ }^{[71,76,78,82-83]}$ (表 5)。

表 5 蓝绿廊道降温效应影响因素

Table 5 Factors influencing the cooling effect of urban greenway and blue corridor

\begin{tabular}{|c|c|}
\hline $\begin{array}{l}\text { 气候区 } \\
\text { Climate zone }\end{array}$ & $\begin{array}{l}\text { 蓝绿基础设施要素特征及其与 LST 定量关系 } \\
\text { Features of green-blue infrastructure elements and their quantitative relationship with LST }\end{array}$ \\
\hline $\begin{array}{l}\mathrm{C} \text { 类/D 类气候区 } \\
\text { C/D climate types }\end{array}$ & 宽度、周边景观配置 \宽度 \结构类型 \宽度 \结构类型 $\backslash$ 时间季节、周边城市形态等 \\
\hline $\begin{array}{l}\text { 内陆带 }(\mathrm{D} \text { 类) : Dwa } \\
\text { Continental }(\mathrm{D} \text { types })\end{array}$ & $\begin{array}{l}\text { - 带状绿地、河流廊道可明显发挥温湿效益的关键宽度为 } 34 \mathrm{~m} \text { 左右 (绿化覆盖率约 } 80 \%)^{[82]} \text { 、 } \\
45 \mathrm{~m} \text { 左右 }{ }^{[44]} \text { 。 } \\
\text { - 河流 (宽度为 } 15 \mathrm{~m} \text { ) 对带状绿地温湿效益的影响范围为 } 28 \mathrm{~m} \text {; 道路(宽度为 } 15 \mathrm{~m} \text { ) 为 } 20 \mathrm{~m}^{[85]}\end{array}$ \\
\hline $\begin{array}{l}\text { 温暖带 }(\mathrm{C} \text { 类 }): \mathrm{Cwa} / \mathrm{Cfb} \\
\text { Temperature }(\mathrm{C} \text { types })\end{array}$ & $\begin{array}{l}\text { - 水面积比例和 LST 存在较高的线性负相关 }\left(R^{2}=-0.72\right) \text {; 河流降温有效范围约 } 200 \mathrm{~m} \text { 左右, 河流 } \\
\text { 越宽, 缓解能力相对越强 } \\
\text { - 河流春季白天平均降温超过 } 1.5^{\circ} \mathrm{C} \text {, 夏天有所降低; 降温水平与周围空气温度, 河流水温, 人射太 } \\
\text { 阳辐射, 风速和相对湿度等因素存在时间和季节依赖性关系; 河岸上的城市形态影响了远离河岸 } \\
\text { 的凉爽程度 }{ }^{883]}\end{array}$ \\
\hline
\end{tabular}

已有研究表明, 河流廊道的低温区域, 其显著的降温距离宽度一般为 $45 \mathrm{~m}$ 左右 ${ }^{[82,84]}$, 其有效降温范围为 $200 \mathrm{~m}$ 左右 ${ }^{[86]}$ 。河流的降温效果具有较强的时间和季节依赖性,在早晨以及水温和气温相差较大的温暖季 节最为明显,夏季水温较高时白天的平均降温幅度有所降低 ${ }^{[83]}$ 。同时, 河岸上的城市形态影响着远离河岸的 降温程度, 街道峡谷提供通往河岸地区的通道, 可在距离河流中心约 30-44 $\mathrm{m}$ 的地方出现最广泛的降 温 ${ }^{\left[{ }^{[2-83]}\right.}$ 。河流、溪流和运河等动态蓝色基础设施通过其流体流动作用, 使它们能够通过平流向下游携带吸收 的辐射,并向城市系统外释放能量 ${ }^{[83]}$ 。研究发现, 下游河流温度相对较高, 且城市河流的日温度波动 更大 ${ }^{[16]}$ 。

带状绿地的宽度及其结构类型均能影响其降温效果。当绿地宽度 $>40 \mathrm{~m}$ 时,绿地内部的降温增湿效果极 其明显且趋于稳定; 当绿化覆盖率约 $80 \%$,城市园林绿地可以明显发挥温湿效益的关键宽度为 $34 \mathrm{~m}$ 左右,可 以显著发挥温湿效益的关键宽度为 $42 \mathrm{~m}$ 左右 ${ }^{[82]}$ 。宽度为 $42 \mathrm{~m}$ 的带状绿地, 当郁闭度超过 $67 \%$ 时, 其降温增 湿效应显著且趋于稳定 ${ }^{[87]}$; 外部为河流时, 其温湿指数相对较低, 舒适性较好 ${ }^{[85]}$ 。中尺度的城市模拟显示, 建造大型的楔形绿地后, 绿地降温距离约为 $1 \mathrm{~km}$, 降低的程度由规划前后的地表类型改变的剧烈程度、风速 大小及与绿地的距离决定 ${ }^{[88]}$ 。

\section{3 群落斑块尺度}

群落斑块尺度上蓝绿基础设施降温效应研究侧重于群落结构和单体植物两方面, 分析郁闭度、叶面积密 度、叶面积指数、三维绿量、树冠大小、树冠风洞、土壤条件等与降温效应的关系 (表 6)。

(1) 群落结构

多数研究针对乔灌草、乔草、乔灌、灌草、乔木、灌木和草地等多种植物群落类型,开展实地观测研究,均证 实乔灌草和乔草型绿地结构具有较好降温效果, 具体降温效果均呈现出乔灌草型>乔草或乔木型>灌草型>草

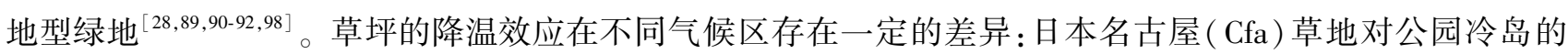
形成有负面影响 ${ }^{[50]}$, 北京 (Dwa) 草坪的降温增湿效应不显著 ${ }^{[87]}$, 太原市 (Dwa) 草坪与片林相比, 草坪的增湿 效果好于降温效果 ${ }^{[89]}$ 。群落结构的乔木盖度、树冠比、树高和郁闭度对其降温效应也存在较大的影 响 ${ }^{[28,66,93]}$ 。有研究表明,大乔木降温效果优于小乔木 $0.2^{\circ} \mathrm{C}$ 以上, 优于灌木 $0.6^{\circ} \mathrm{C}$ 以上 ${ }^{[66]}$; 群落结构中每增加 $10 \%$ 的树冠比, 降温效果增加 $0.2^{\circ} \mathrm{C}^{[28]}$; 郁闭度接近 0.85 时, 夏季降温能力达到最大 ${ }^{[91]}$; 郁闭度每增加 $10 \%$, 
降温效果增加 $0.5^{\circ} \mathrm{C}$; 树高每增加 $10 \mathrm{~cm}$, 降温效果增加 $0.05^{\circ} \mathrm{C}^{[93]}$ 。不同植物、建筑空间配置(形状, 排列和布 局) 也会影响群落的整体降温效果, 破碎程度、形状复杂性、绿带方向和植被类型对绿地的降温效果均有影 响 ${ }^{[28,101]}$; 具有较大树冠、平行于风向的带状绿色区域,最大降温效果可达 $6.3 \mathrm{~K}^{[101]}$ 。此外, 在建筑垂直绿化方 面, 单一植物降温效应优于多种植物混合的降温效应 ${ }^{[97]}$ 。

\section{表 6 群落斑块尺度城市蓝绿基础设施降温效应影响因素}

Table 6 Factors influencing the cooling effect of urban green space in community patch scale

\begin{tabular}{|c|c|c|}
\hline \multirow{2}{*}{$\begin{array}{l}\text { 气候区 } \\
\text { Climate zone }\end{array}$} & \multicolumn{2}{|c|}{$\begin{array}{c}\text { 蓝绿基础设施要素特征及其与 LST 定量关系 } \\
\text { Features of green-blue infrastructure elements and their quantitative relationship with LST }\end{array}$} \\
\hline & 群落结构 Community structure & 单体植物 Plant \\
\hline $\begin{array}{l}\mathrm{C} \text { 类 } / \mathrm{D} \text { 类气候区 } \\
\mathrm{C} / \mathrm{D} \text { climate types }\end{array}$ & $\begin{array}{l}\text { 植物配置、郁闭度、绿量 } \backslash \text { 植物配置 } \backslash \text { 植物配置、结构类 } \\
\text { 型 } 、 \text { 植物配置〉郁闭度、LAI、树高、胸径、密度、树干断 } \\
\text { 面积 植物配置、类型、时间、植物配置、枝叶茂密度、 } \\
\text { 植物配置 }\end{array}$ & 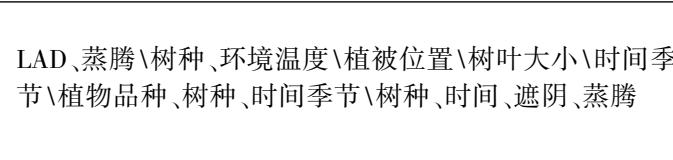 \\
\hline $\begin{array}{l}\text { 内陆带 }(\mathrm{D} \text { 类 }): \mathrm{Dfa} / \\
\text { Dwa/Dfb } \\
\text { Continental (D types) }\end{array}$ & $\begin{array}{l}\text { - 降温效应: 复层结构绿地 }>\text { 单层结构的绿地 }{ }^{[89]} \text {; 乔 } \\
\text { 灌草型>灌草型/草坪型绿地 }{ }^{[90]} \text { 。 } \\
\text { - 绿地夏季日均降温幅度 } 0.2-2.0^{\circ} \mathrm{C} \text {; 降温影响: 郁 } \\
\text { 闭度>绿量 }{ }^{[91]} \text { 。 } \\
\text {-与片林相比, 草坪的增湿效果好于降温效果 }{ }^{[92]} \text { 。 } \\
\text { - 郁闭度及树高与降温强度呈线性正相关; LAI 与降 } \\
\text { 温强度呈非线性正相关, LAI 对降温调节功能存在作 } \\
\text { 用阈值, 为 } 0.23-2.3^{\circ} \mathrm{C}^{[93]}\end{array}$ & $\begin{array}{l}\text { - } \mathrm{LAD} \text { 每增加一个单位, LST 降低 } 4.63 \mathrm{~K} \text {; 高叶面积密度 } \\
\text { 和高蒸腾速率的树木有更多的降温 }{ }^{[94]} \text { 。 } \\
\text { - 㿝荚树能够在极端温度下保持相对恒定的叶片温度; } \\
\text { 随着气温升高, 小叶椴降温效果高于刺槐 }[91] \text { 。 } \\
\text { - 五叶地锦在正午前的顶、南、东、西、北面绿化分别降 } \\
\text { 低温度 } 5.77^{\circ} \mathrm{C} 、 4.45^{\circ} \mathrm{C} 、 4.21^{\circ} \mathrm{C} 、 3.36^{\circ} \mathrm{C} 、 1.6^{\circ} \mathrm{C}^{[95]} \text { 。 } \\
\text { - 四种景天可将峰值土壤温度降低 } 5-7^{\circ} \mathrm{C}^{[96]}\end{array}$ \\
\hline $\begin{array}{l}\text { 温暖 带 ( C 类 ) : Cfa/ } \\
\text { Cwa/Cfb } \\
\text { Temperature ( C types ) }\end{array}$ & $\begin{array}{l}\text { - 绿萝+常春藤+花叶扶芳藤+常春油麻藤综合降温 } \\
4.1^{\circ} \mathrm{C}[97] \text { 降 } \\
\text { - 降温效应: 林地>草地。树木覆盖能够最高降低空 } \\
\text { 气温度 } 2.7 \mathrm{~K} \text {, 平均辐射温度 } 39.1 \mathrm{~K} \text {, 平均生理等效温 } \\
\text { 度最高 } 17.4 \mathrm{~K} \text { [98] }\end{array}$ & 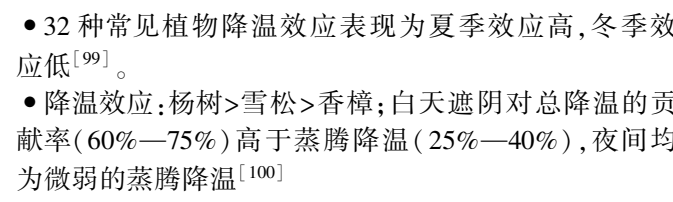 \\
\hline
\end{tabular}

LAD: 叶面积密度 Leaf-area density

\section{(2) 单体植物}

单体植物方面,不同气候区植被的类型存在较大的差异,因而其降温环境效应存在较大的不同。详细的， 由于在胸径、边材面积、树高、冠层高度、冠幅、叶面积指数、气孔导度、树干液流、树冠风洞等生物性状差异, 单 体植物降温效果差异明显 ${ }^{[94,100,102-103]}$, 且其遮荫作用 $(60 \%-75 \%)$ 对总降温的贡献率大于蒸腾作用 $(25 \%$ $40 \%)^{[94]}$ 。研究表明, 具有高叶面积密度、高蒸腾速率的树木更能有效地降低空气温度, 如土耳其榛和欧洲小 叶椴等 ${ }^{[94]}$, 具有较高叶面积指数和树木边材面积的小叶椴树提供的蒸腾量是刺槐的 3 倍 ${ }^{[103]}$ 。拥有纸质叶片 结构的植物基本蒸腾降温能力较强, 其蒸腾强度白天为 $0.15-2.5 \mathrm{~g} \mathrm{dm}^{-2} \mathrm{~h}^{-1}$, 蒸腾速率> $3.5 \mathrm{mmol} \mathrm{m}^{-2} \mathrm{~s}^{-1[66]}$ 。 叶子较小的植物在高环境温度条件下能够保持相对凉爽 ${ }^{[102]}$ 。例如, 美国㿝荚可以在极端温度下保持相对恒 定的叶面温度 ${ }^{[102]}$; 景天属植物在夏季缺水期间会降低土壤温度峰值并提高邻近植物的生长性能 ${ }^{[96]}$ 。

此外,单体植物的种植位置、自身阴影、季节因素等均影响其降温效果 ${ }^{[95,99-100,103]}$ 。如周围为公园的树木 其降温效果明显高于周围为硬质铺装的树木 ${ }^{[102]}$; 五叶地锦, 平均降温距离为 $40 \mathrm{~cm}$, 在正午前后降温极显著, 建筑各面降温范围: 顶面>南面>东面>西面>北面 ${ }^{[95]}$; 完全暴露在阳光下的地区比树荫地区的表面温度高出 $15.2 \mathrm{~K}^{[94]}$; 成都市 32 种立体绿化树种蒸腾降温效应呈现夏季效应高, 冬季效应低,春秋两季能力中的季节性 规律变化 ${ }^{[99]}$ 。

\section{3 降温效应研究对蓝绿基础设施规划设计的启示}

基于现有蓝绿基础设施降温效应研究成果,依据规划设计层次,从热环境优化视角开展蓝绿基础设施规 划设计实践 (表 7), 将会有助于增强城市应对气候变化的韧性,增强居民应对热岛效应的适应力,提升蓝绿基 础设施对人类健康和福祉的贡献。 
3.1 对蓝绿基础设施总体规划启示

蓝绿基础设施总体规划对应我国城市绿地系统规划实践。以缓解城市热岛效应为导向,城市绿地系统规 划可从以下几个方面考虑: (1) 基于不同气候区景观环境特征,配合城市地域国土空间规划,顺应城市山水骨 架, 依据景观尺度上蓝绿基础设施降温效应及其覆被性状关系研究成果, 合理修订城市绿地率、绿地覆盖率发 展目标。例如,有研究表明当生态用地占比达到 $70 \%$ 时, UHI 缓解作用显著 ${ }^{[19]}$; 植被覆盖率占比在 $70 \%-$ $80 \%$ 的地区具有显著而强烈的降温效果 ${ }^{[24]}$ 。但以上各类覆被指标如何与规划中绿地率、绿地覆盖率等指标 相互对应, 仍值得进一步深人分析。(2) 结合城市发展目标、水敏性城市设计、立体绿化系统和通风廊道构 建 ${ }^{[104]}$,形成多功能的蓝绿基础设施网络,适应性地指导街道绿化工程设计与建设。例如,水敏性城市设计可 有效增加城市地表土壤水分渗透与补给, 最大限度地利用现有植被和绿色空间的城市气候效益 ${ }^{[11]}$ 。结合绿 色屋顶 ${ }^{[105]}$ 和立体绿化系统 ${ }^{[71]}$, 可有效缓解城市热岛, 并实现建筑物 32\%-100\%的节能 ${ }^{[52]}$ 。(3) 通过水体和 绿地等景观元素体系的相互作用, 实现协同降温效应的最大化, 增强街区气候适应能力。已有研究表明,通过 规划滨水植被景观, 可将热舒适性改善区域扩展 10-20 $\mathrm{m}^{[77]}$; 而设计不良的蓝色基础设施可能会在压迫性条 件下加剧热应激 ${ }^{[16]}$; 外部环境为河流的带状绿地温湿度指数值相对较低, 舒适性较好 ${ }^{[85]}$ 。

表 7 蓝绿基础设施降温规划设计启示

Table 7 Inspiration of green and blue infrastructure cooling planning and design

\begin{tabular}{|c|c|c|c|c|}
\hline $\begin{array}{l}\text { 尺度 } \\
\text { Scale }\end{array}$ & $\begin{array}{l}\text { 适应性优化方向 } \\
\text { Thermal environment optimization }\end{array}$ & $\begin{array}{l}\text { 蓝绿基础设施图示 } \\
\text { Green and blue infrastructure visual }\end{array}$ & & \\
\hline $\begin{array}{l}\text { 总体规划 } \\
\text { Master planning }\end{array}$ & $\begin{array}{l}\text { - 基于城市山水骨架, 合理规划蓝绿基 } \\
\text { 础设施定量指标,优化蓝绿基础设施空 } \\
\text { 间布局, 指导适应性的雨洪管理、立体 } \\
\text { 绿化、街道及河岸带绿化等工程设计与 } \\
\text { 建设,强化蓝绿基础设施的多功能性 }\end{array}$ & 顺应城市山水骨架 & 优化蓝绿空间布局 & 指导蓝绿空间设计 \\
\hline $\begin{array}{l}\text { 场地规划 } \\
\text { Site planning }\end{array}$ & $\begin{array}{l}\text { - 基于控规指标 (环境容量、建筑引 } \\
\text { 导), 结合场地肌理形态、土地利用政 } \\
\text { 策、现状环境评估等, 规划场地降温措 } \\
\text { 施布局, 提高景观元素的连通性, 增强 } \\
\text { 水体和绿地的协同降温效应, 改善场地 } \\
\text { 降温结构 }\end{array}$ & 梳理场地肌理 提升景观连通性 & 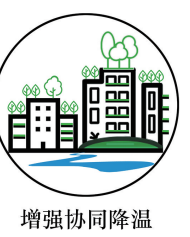 & 改善降温结构 \\
\hline $\begin{array}{l}\text { 场地设计 } \\
\text { Site design }\end{array}$ & $\begin{array}{l}\text { - 结合场地现状, 从材料、色彩、样式等 } \\
\text { 方面进行热缓解设计; 统筹建筑空间组 } \\
\text { 合、垂直绿化设置、绿地植物设计, 改善 } \\
\text { 居住环境; 选择高降温增湿效率的植物 } \\
\text { 品质, 优化植物种植形式和群落结构 }\end{array}$ & 建筑空间组合 & 垂直绿化设置 & 植物景观设计 \\
\hline
\end{tabular}

3.2 对蓝绿基础设施场地规划的启示

为进一步引导城市蓝绿基础设施场地规划, 此处借助 Meta 分析 (Meta-Analysis) 方法 ${ }^{[106-107]}$ 统计不同气 候条件下城市公园绿地的降温效果及其关键格局特征。根据已检索的与公园绿地降温效应有关的期刊论文, 排除未采用定量分析、没有明确绿地边界和重复发表的文献, 人选文章包括 12 篇, 涉及 329 个公园, 主要位于 C 类 (温暖带) 和 D 类 (内陆带)气候区, 研究时间集中在夏季。使用 RevMAN5.3 对上述文献进行 Meta 分析 发现, 不同气候区公园绿地降温效应亦不同: $\mathrm{C}$ 类 ${ }^{[16,50-51,57,108-110]}$ 气候区平均公园降温强度为 $1.93{ }^{\circ} \mathrm{C}\left(\mathrm{I}^{2}=88 \%\right.$, $\mathrm{CI}=[1.19,2.66]), \mathrm{D}$ 类 ${ }^{[48-49,53,111-112]}$ 气候区平均公园降温强度为 $3.12^{\circ} \mathrm{C}\left(\mathrm{I}^{2}=75 \%, \mathrm{CI}=[2.06,4.18]\right)($ 图 4)。 对比 Bowler 等 ${ }^{[113]}$ 的公园绿地降温效应 Meta 分析中 $\mathrm{C}$ 类气候区平均降温水平 $\left(0.79^{\circ} \mathrm{C}\right)$ 以及 Volker 等 ${ }^{[114]}$ 通 过 Meta 分析得到蓝色空间的平均降温效果 $(2.5 \mathrm{~K})$ 可知, 即使在同一气候区城市公园绿地降温效果也有差 异。进一步对影响公园绿地降温效应的面积大小、形状、内部组成等规划设计参数进行统计发现, 公园绿地面 积对其降温效应影响特征较为显著; 例如在 $\mathrm{C}$ 类和 D 类气候区, 面积大于 $1 \mathrm{~km}^{2}$ 的公园绿地平均降温分别为 
$3.99^{\circ} \mathrm{C}$ 和 $4.02^{\circ} \mathrm{C}$, 面积为 $0.5-1 \mathrm{~km}^{2}$ 的公园绿地平均降温分别为 $3.30^{\circ} \mathrm{C}$ 和 $3.23^{\circ} \mathrm{C}$, 面积小于 $0.5 \mathrm{~km}^{2}$ 的公园绿 地平均降温分别为 $3.22^{\circ} \mathrm{C}$ 和 $2.49^{\circ} \mathrm{C}$; 而其他因素的影响特征尚不一致。因此, 未来应加强城市公园绿地降温 效果方面的定量研究,以高效指导规划建设实践、提升公园绿地热缓解效果。

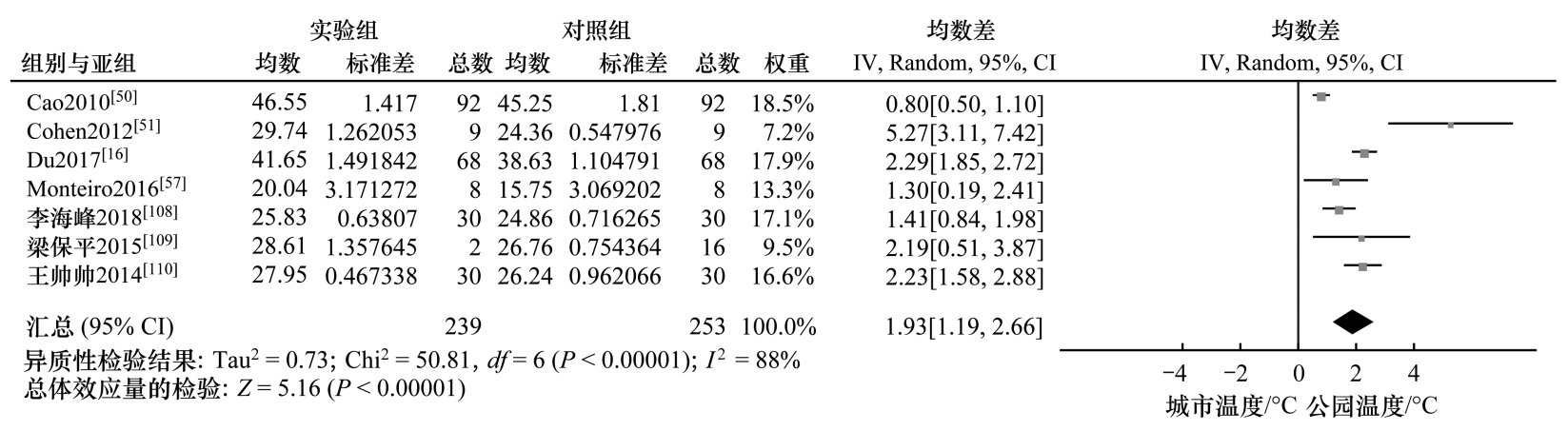

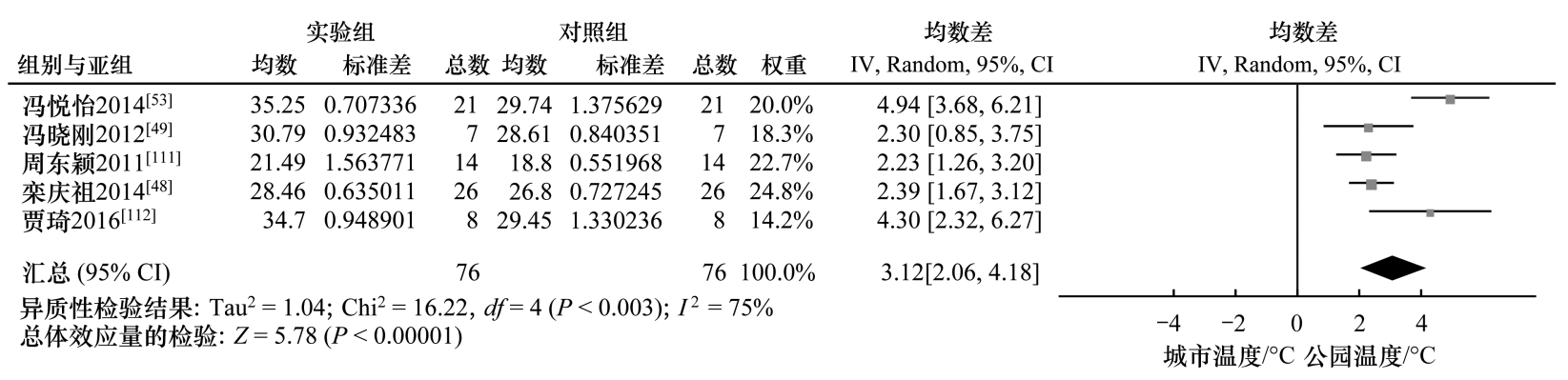

图 4 公园绿地降温效应 Mate 分析

Fig.4 Mate analysis of cooling effect of park green space

根据以上定量分析结果,蓝绿基础设施场地规划可结合我国控制性详细规划及相关指标控制与引导 (如 绿地率、地块面积、建筑密度、建筑高度), 提升其降温效果: (1) 蓝绿基础设施景观元素布设时,宜优先选择分 散型布置方式, 尽量布置于有大面积热岛存在的区域 ${ }^{[5]}$; 在降温阈值范围内景观元素的面积、周长和形状指 数越大越好 ${ }^{[115]}$; 绿地元素宜选择较优森林结构、较高降温效率的植物群落组合; 水体元素宜增加水文连通 性, 优化周边植物景观配置, 增强协同降温效应。(2)在高密度建成区内, 可控制地块土地利用模式、优化建 筑高度、建筑密度和面积来缓解城市热岛 ${ }^{[20,116-117]}$; 例如有研究显示采用区划 (Zoning) 和土地细分 (Subdivision) 控制街区规模和居住区大小和建筑材料等, 能够将其对区域热环境的贡献减少约 $40 \%{ }^{[117]}$; 在 C 类气候区 (温暖带) 中当绿地率为 30\%、容积率为 2.5-3.5 时的控制性详细规划地块对热环境的影响最 小 ${ }^{[116]}$ 。但相关定量研究数量极为有限, 未来应加强街区尺度蓝绿基础设施降温效果与控制性详细规划指标 相互关联方面的研究。

3.3 对蓝绿基础设施场地设计的启示

蓝绿基础设施场地设计主要对应各类城市绿地设计, 在此以与居民热舒适性密切相关的公园绿地设计和 附属绿地设计为例。(1) 公园绿地设计时, 应结合场地现状与设计目标, 最小化不透水面比例, 增加绿地和水 体面积。地形设计应结合竖向控制及其周边环境要素进行通风道和防风屏的设计,辅助优化和改善局地热环 境; 铺装设计宜采用透水材料并结合雨洪设施布局以控制硬质铺装集中连片, 通过增强地表透水性能和水分 滞蓄能力调节水分蒸发和热量蒸散; 建筑物及构筑物方面, 通过高反光材料、遮荫作用、冷暖感官色彩调节等 增强热舒适的人体生理感受。(2) 附属绿地设计时, 应统筹建筑空间组合、绿地设置及绿化设计, 优化居住区 的风环境; 同时结合建筑垂直绿化和屋顶绿化, 采用具有高反射率叶面的植物, 减轻建筑能耗压力, 调节社区 生态环境和能量平衡。通过实测最大降温效应、模拟预测不同植物选择图谱的降温效应 ${ }^{[18]}$ 、模拟不同场景 的降温效应 ${ }^{[119]}$ 等方面进行设计方案的优化, 从而提高其对周边热环境的调节作用。(3) 种植设计时, 宜优先 
选择布设乔木盖度高、混交林型、乔灌草和乔草型绿地群落结构, 尽可能增加树冠比和树高, 有研究显示郁闭 度介于 $0.60-0.85$ 、三维绿量密度 $\geqslant 5 \mathrm{~m}^{3} / \mathrm{m}^{2}$ 的植物群落具有较好的降温效果 ${ }^{[91]}$; 植物选择除根据当地气候 特征及乡土植物进行优选外, 优先选择叶面积密度高、蒸腾速率高、纸质叶片结构等高降温特性的植物品种; 在布局方式上选择同场地日照阴影走向和风向一致的方位进行布置以增强通风。

\section{4 结论与展望}

作为城市应对气候变化中一类典型的基于自然的解决方案, 蓝绿基础设施已成为城市环境、社会和经济 可持续发展所需的多尺度生态框架。未来城市蓝绿基础设施降温效应研究可从以下几方面继续深化。

(1) 基于气候区特征, 衔接城市和街区尺度上蓝绿基础设施降温效应研究, 笁选关键的蓝绿基础设施热 缓解参数, 指导城市绿地系统规划定量指标的设定等。现有蓝绿基础设施降温效应研究已在城市景观格局演 变与热岛效应两者间的定量关系方面取得进展, 已明确蓝绿景观面积占比与热岛效应之间的定量关系, 但对 于蓝绿景观内部要素构成变化对城市热环境的影响缺乏定量研究,不利于指导蓝绿基础设施规划设计实践。 未来研究可进一步深人跨尺度城市蓝绿基础设施降温效应研究,在明确不同景观面积配比关系的基础上,揭 示街区尺度上内部景观要素组成变化对城市热环境的影响机制, 优选蓝绿基础设施以抵消城市扩张本身对气 候的影响,并针对不同街区类型提出适应解决方案之间的权衡原则, 预测未来优选城市蓝绿基础设施规划对 街区热岛效应的缓解作用, 以衔接大范围的城市和街区热岛缓解。最终通过景观空间形态指标与降温效应规 划标准相结合,用于指导城市蓝绿基础设施的规划设计。

(2) 构建城市蓝绿基础设施多维度立体空间, 关注其降温效应的水平分布与垂直传输之间的联系,结合 街区热环境特征,指导城市蓝绿基础设施控制性详细规划指标。虽然大量研究分析了城市蓝绿基础设施降温 效应随距离变化的水平分布规律, 或随高度变化的垂直分布规律, 但对降温效应水平分布与垂直传输之间的 相互联系与作用机理尚不清楚, 且少有定量证据能够阐明蓝绿基础设施是如何影响街区整体气候特征。未来 应加强垂直冷却分布监测数据的收集, 进行垂直运输时间模式所必需的纵向分析, 同时结合水平输送过程, 进 行多维度立体空间降温效应的研究。因此, 未来相关研究应结合街区热环境特征, 确定场地降温阈值, 配合高 效降温的蓝绿基础设施布局结构,优化城市蓝绿基础设施控制性详细规划指标; 最终通过蓝绿斑块的合理分 布,构建水平与垂直传输之间的流通渠道, 减轻城市热岛的不利影响,增强城市气候韧性。

(3) 针对场地设计, 选取降温能力较强的植物, 以配置降温效率较高的植物群落。已有的研究表明, 植物 群落降温效应具有动态可变性, 不同植物群落配置可以强烈地影响其冷却效果, 但多缺乏针对不同类型绿地 内的群落降温效益研究, 同时对群落空间配置的关键因子缺乏判定; 单个树种方面的研究也多为不同树种的 降温统计, 对影响其降温效率差异的关键的植物种植设计因素研究不足, 同时缺乏其对群落的降温贡献研究。 因而未来应在关键因子识别、空间配置影响等方面确定街区不同绿地类型内特有植物群落配置的降温效益, 识别最优降温群落的单体植物配置, 同时注重探究影响不同植物降温效率差异的核心元素。如针对不同类型 的林地、湿地、公园绿地、附属绿地、城市广场、街旁绿地等的植物群落配置降温特点; 不同植物的 C3 代谢和 C4 代谢对蒸散降温的影响、气孔阻力、芽和根的液压抗性、土壤条件和背景气候因素等。以期通过这些研究 指导蓝绿基础设施在未来城市增长战略中的应用方式。

参考文献 (References) :

[ 1 ] Tzoulas K, Korpela K, Venn S, Yli-Pelkonen V, Kazmierczak A, Niemela J, James P. Promoting ecosystem and human health in urban areas using Green Infrastructure: a literature review. Landscape and Urban Planning, 2007, 81(3) : 167-178.

[ 2 ] 徐涵秋. 基于城市地表参数变化的城市热岛效应分析. 生态学报, 2011, 31(14): 3890-3901.

[ 3 ] Akbari H, Kolokotsa D. Three decades of urban heat islands and mitigation technologies research. Energy and Buildings, 2016, 133: 834-852.

[ 4 ] Patz J A, Campbell-Lendrum D, Holloway T, Foley J A. Impact of regional climate change on human health. Nature, 2005, 438(7066) : 310-317.

[ 5 ] Norton B A, Coutts A M, Livesley S J, Harris R J, Hunter A M, Williams N S G. Planning for cooler cities: a framework to prioritise green 
infrastructure to mitigate high temperatures in urban landscapes. Landscape and Urban Planning, 2015, 134: $127-138$.

[6] Lowe S A. An energy and mortality impact assessment of the urban heat island in the US. Environmental Impact Assessment Review, 2016, 56: 139- 144 .

[ 7 ] Bi P, Williams S, Loughnan M, Lloyd G, Hansen A, Kjellstrom T, Dear K, Saniotis A. The Effects of Extreme Heat on Human Mortality and Morbidity in Australia: Implications for Public Health. Asia Pacific Journal of Public Health, 2011, 23( S2) : 27S-36S.

[ 8 ] Guindon S M, Nirupama N. Reducting risk from urban heat island effects in cities. Natural Hazards, 2015, 77(2): 823-831.

[ 9 ] Matthews T, Lo A Y, Byrne J A. Reconceptualizing green infrastructure for climate change adaptation: barriers to adoption and drivers for uptake by spatial planners. Landscape and Urban Planning, 2015, 138: 155-163.

[10] Sandström U F. Green Infrastructure planning in urban Sweden. Planning Practice \& Research, 2002, $17(4): 373-385$.

[11] Coutts A M, Tapper N J, Beringer J, Loughnan M, Demuzere M. Watering our Cities: the capacity for Water Sensitive Urban Design to support urban cooling and improve human thermal comfort in the Australian context. Progress in Physical Geography, 2013, 37 (1) : 2-28.

[12] Voskamp I M, Van de Ven F H M. Planning support system for climate adaptation: composing effective sets of blue-green measures to reduce urban vulnerability to extreme weather events. Building and Environment, 2015, 83: 159- 167.

[13] Gill S E, Handley J F, Ennos A R, Pauleit S. Adapting cities for climate change: the role of the green infrastructure. Built Environment, 2007, 33 (1) : 115-133.

[14] Gunawardena K R, Wells M J, Kershaw T. Utilising green and bluespace to mitigate urban heat island intensity. Science of the Total Environment, 2017, 584-585: 1040-1055.

[15] 余兆武, 郭青海, 孙然好. 基于景观尺度的城市冷岛效应研究综述. 应用生态学报, 2015, 26(2):636-642.

[16] Du H Y, Cai W B, Xu Y Q, Wang Z B, Wang Y Y, Cai Y L. Quantifying the cool island effects of urban green spaces using remote sensing Data. Urban Forestry \& Urban Greening, 2017, 27: 24-31.

[17] Walmsley A. Greenways: multiplying and diversifying in the 21st century. Landscape and Urban Planning, 2006, 76( 1/4): 252-290.

[18] Li X M, Zhou W Q, Ouyang Z Y. Relationship between land surface temperature and spatial pattern of greenspace: what are the effects of spatial resolution. Landscape and Urban Planning, 2013, 114: 1-8.

[19] Peng J, Xie P, Liu Y X, Ma J. Urban thermal environment dynamics and associated landscape pattern factors: a case study in the Beijing metropolitan region. Remote Sensing of Environment, 2016, 173: 145-155.

[20] Li J X, Song C H, Cao L, Zhu F G, Meng X L, Wu J G. Impacts of landscape structure on surface urban heat islands : a case study of Shanghai, China. Remote Sens Environ. Remote Sensing of Environment, 2011, 115(12) : 3249-3263.

[21] 裔传祥, 胡继超, 李小军. 土地覆盖类型对城市热岛效应的响应分析. 测绘通报, 2018, (1): 72-76, 116-116.

[22] Chen X L, Zhao H M, Li P X, Yin Z Y. Remote sensing image-based analysis of the relationship between urban heat island and land use/cover changes. Remote Sensing of Environment, 2006, 104(2) : 133-146.

[23] Tan M H, Li X B. Integrated assessment of the cool island intensity of green spaces in the mega city of Beijing. International Journal of Remote Sensing, 2013, 34(8): 3028-3043.

[24] Alavipanah S, Wegmann M, Qureshi S, Weng Q H, Koellner T. The Role of vegetation in mitigating urban land surface temperatures: a case study of Munich, Germany during the warm season. Sustainability, 2015, 7(4): 4689-4706.

[25］梁保平, 翟禄新. 1991-2006 年桂林市植被覆盖度、地表温度时空变化及相关性研究. 中国园林, 2014, 30(7)：77-81.

[26] 曹璐, 胡瀚文, 孟宪否, 李俊祥. 城市地表温度与关键景观要素的关系. 生态学杂志, 2011, 30(10): 2329-2334.

[27] Kim Y, An S M, Eum J H, Woo J H. Analysis of thermal environment over a small-scale landscape in a densely built-up Asian megacity. Sustainability, 2016,8(4): 358 .

[28］章莉, 詹庆明, 蓝玉良. 武汉市居住用地绿地降温效应研究. 中国园林, 2018, 34(4): 47-53.

[29] 陈墅香, 陈溢晨, 刘塨. 日温影响下校园人工湿地生态降温规律研究——以华侨大学厦门校区为例. 中外建筑, 2015 , ( 8) : 60-62.

[30］刘艳红, 郭晋平, 魏清顺. 基于 CFD 的城市绿地空间格局热环境效应分析. 生态学报, 2012, 32(6): 1951-1959.

[31］黄玉贤, 陈俊良, 童杉姗. 利用城市绿化缓解新加坡热岛效应方面的研究. 中国园林, 2018, 34(2): 13-17.

[32］洪波，林波荣. 基于实测和模拟的居住小区冬季植被优化设计研究. 中国园林, 2014, 30(9): 104-108.

[33] Zhao L, Lee X H, Smith R B, Oleson K. Strong contributions of local background climate to urban heat islands. Nature, 2014, 511 ( 7508) : 216-219.

[34] Yu Z W, Xu S B, Zhang Y H, Jørgensen G, Vejre H. Strong contributions of local background climate to the cooling effect of urban green vegetation. Scientific Reports, 2018, 8(1): 6798.

[35] Peel M C, Finlayson B L, McMahon T A. Updated world map of the Köppen-Geiger climate classification. Hydrology and Earth System Sciences, 2007, 11(5): 1633-1644. 
[36] Sun R H, Chen L D. Effects of green space dynamics on urban heat islands: Mitigation and diversification. Ecosystem Services, 2017,23 : 38-46.

[37] Sun R H, Chen L D. How can urban water bodies be designed for climate adaptation? Landscape and Urban Planning, 2012 , 105 (1/2) : 27-33.

[38] Hardin P J, Jensen R R. The effect of urban leaf area on summertime urban surface kinetic temperatures: a Terre Haute case study. Urban Forestry \& Urban Greening, 2007, 6(2): 63-72.

[39] Du S H, Xiong Z Q, Wang Y C, Guo L. Quantifying the multilevel effects of landscape composition and configuration on land surface temperature. Remote Sensing of Environment, 2016, 178: 84-92.

[40] Estoque R C, Murayama Y, Myint S W. Effects of landscape composition and pattern on land surface temperature: an urban heat island study in the megacities of Southeast Asia. Science of the Total Environment, 2017, 577: 349-359.

[41] 张彪, 高吉喜, 谢高地, 王艳萍. 北京城市绿地的蒸腾降温功能及其经济价值评估. 生态学报, 2012, 32(24) : 7698-7705.

[42] Moss J L, Doick K J, Smith S, Shahrestani M. Influence of evaporative cooling by urban forests on cooling demand in cities. Urban Forestry \& Urban Greening, 2019, 37: 65-73.

[43] Georgescu M, Morefield P E, Bierwagen B G, Weaver C P. Urban adaptation can roll back warming of emerging megapolitan regions. Proceedings of the National Academy of Sciences of the United States of America, 2014, 111(8) : 2909-2914.

[44] Chen A L, Yao X A, Sun R H, Chen L D. Effect of urban green patterns on surface urban cool islands and its seasonal variations. Urban Forestry \& Urban Greening, 2014, 13(4): 646-654.

[45] 邵世维, 肖立霞, 刘辉. 利用遥感影像探索土地利用与城市热岛的关系. 地理空间信息, 2018, 16(1): 86-90.

[46] Sun R H, Lü Y H, Chen L D, Yang L, Chen A L. Assessing the stability of annual temperatures for different urban functional zones. Building and Environment, 2013, 65: 90-98.

[47] 朱春阳. 城市湖泊湿地温湿效应——以武汉市为例. 生态学报, 2015, 35(16) : 5518-5527.

[48] 奕庆祖, 叶彩华, 刘勇洪, 李书严, 高燕虎. 城市绿地对周边热环境影响遥感研究一一以北京为例. 生态环境学报, 2014,23 ( 2 ) : 252-261.

[49］冯晓刚, 石辉. 基于遥感的夏季西安城市公园“冷效应”研究. 生态学报, 2012, 32(23): 7355-7363.

[50] Cao X, Onishi A, Chen J, Imura H. Quantifying the cool island intensity of urban parks using ASTER and IKONOS data. Landscape and Urban Planning, 2010, 96(4): 224-231.

[51] Cohen P, Potchter O, Matzarakis A. Daily and seasonal climatic conditions of green urban open spaces in the Mediterranean climate and their impact on human comfort. Building and Environment, 2012, 51: 285-295.

[52] Alexandri E, Jones P. Temperature decreases in an urban canyon due to green walls and green roofs in diverse climates. Building and Environment, $2008,43(4): 480-493$.

[53] 冯悦怡, 胡潭高, 张力小. 城市公园景观空间结构对其热环境效应的影响. 生态学报, 2014, 34(12): 3179-3187.

[54] Ren Z B, He X Y, Zheng H F, Zhang D, Yu X Y, Shen G Q, Guo R H. Estimation of the relationship between urban park characteristics and park cool island intensity by remote sensing data and field measurement. Forests, 2013, 4(4): 868-886.

[55] Ren Z B, He X Y, Pu R L, Zheng H F. The impact of urban forest structure and its spatial location on urban cool island intensity. Urban Ecosystems, 2018, 21(5): 863-874.

[56] 苏泳娴, 黄光庆, 陈修治, 陈水森. 广州市城区公园对周边环境的降温效应. 生态学报, 2010, 30(18): 4905-4918.

[57] Monteiro M V, Doick K J, Handley P, Peace A. The impact of greenspace size on the extent of local nocturnal air temperature cooling in London. Urban Forestry \& Urban Greening, 2016, 16: 160-169.

[58] Doick K J, Peace A, Hutchings T R. The role of one large greenspace in mitigating London's nocturnal urban heat island. Science of the Total Environment, 2014, 493: 662-671.

[59] Oliveira S, Andrade H, Vaz T. The cooling effect of green spaces as a contribution to the mitigation of urban heat: a case study in Lisbon. Building and Environment, 2011, 46(11): 2186-2194.

[60] Skoulika F, Santamouris M, Kolokotsa D, Boemi N. On the thermal characteristics and the mitigation potential of a medium size urban park in Athens, Greece. Landscape and Urban Planning, 2014, 123: 73-86.

[61] Yu C, Hien W N. Thermal benefits of city parks. Energy and Buildings, 2006, 38(2) : 105-120.

[62] Vidrih B, Medved S. Multiparametric model of urban park cooling island. Urban Forestry \& Urban Greening, 2013, 12(2) : $220-229$.

[63] Ca V T, Asaeda T, Abu E M. Reductions in air conditioning energy caused by a nearby park. Energy and Buildings, 1998, 29 (1) : 83-92.

[64] Coseo P, Larsen L. How factors of land use/land cover, building configuration, and adjacent heat sources and sinks explain Urban Heat Islands in Chicago. Landscape and Urban Planning, 2014, 125: 117-129.

[65] Susca T, Gaffin S R, Dell'Osso G R. Positive effects of vegetation: urban heat island and green roofs. Environmental Pollution, 2011, 159( 8/9) : 2119-2126. 
[66] 高凯, 秦俊, 胡永红. 上海城市居住区绿化缓解热岛效应研究进展. 中国园林, 2010, 26(12) : 12-15.

[67] Yokohari M, Brown R D, Kato Y, Yamamoto S. The cooling effect of paddy fields on summertime air temperature in residential Tokyo, Japan. Landscape and Urban Planning, 2001, 53(1/4): 17-27.

[68] Kikegawa Y, Genchi Y, Kondo H, Hanaki K. Impacts of city-block-scale countermeasures against urban heat-island phenomena upon a building's energy-consumption for air-conditioning. Applied Energy, 2006, 83(6): 649-668.

[69] Cuce E. Thermal regulation impact of green walls: an experimental and numerical investigation. Applied Energy, 2016, 194: 247-254.

[70] Berardi U. The outdoor microclimate benefits and energy saving resulting from green roofs retrofits. Energy and Buildings, 2016, 121: $217-229$.

[71] Wong N H, Tan A Y K, Tan P Y, Sia A, Wong N C. Perception studies of vertical greenery systems in Singapore. Journal of Urban Planning and Development, 2010, 136(4) : 330-338.

[72] Middel A, Chhetri N, Quay R. Urban forestry and cool roofs: assessment of heat mitigation strategies in Phoenix residential neighborhoods. Urban Forestry \& Urban Greening, 2015, 14(1): 178-186.

[73] Theodosiou T. Green Roofs in Buildings: thermal and environmental behaviour. Advances in Building Energy Research, 2009, 3(1) : $271-288$.

[74] Feitosa R C, Wilkinson S J. Attenuating heat stress through green roof and green wall retrofit. Building and Environment, 2018 , $140: 11-22$.

[75] Xue Z S, Hou G L, Zhang Z S, Lyu X, Jiang M, Zou Y C, Shen X J, Wang J, Liu X H. Quantifying the cooling-effects of urban and peri-urban wetlands using remote sensing data: case study of cities of Northeast China. Landscape and Urban Planning, 2019, 182: 92-100.

[76] 岳文泽, 徐丽华. 城市典型水域景观的热环境效应. 生态学报, 2013, 33(6): 1852-1859.

[77] Xu J C, Wei Q L, Huang X F, Zhu X Y, Li G M. Evaluation of human thermal comfort near urban waterbody during summer. Building and Environment, 2010, 45(4): 1072-1080.

[78] 张棋斐, 文雅, 吴志峰, 陈颖彪. 高密度建成区湖泊水体的热缓释效应及其季相差异一以广州市中心城区为例. 生态环境学报, 2018, 27(7) : 1323-1334.

[79] Steeneveld G J, Koopmans S, Heusinkveld B G, Theeuwes N E. Refreshing the role of open water surfaces on mitigating the maximum urban heat island effect. Landscape and Urban Planning, 2014, 121: 92-96.

[ 80] Theeuwes N E, Solcerová A, Steeneveld G J. Modeling the influence of open water surfaces on the summertime temperature and thermal comfort in the city. Journal of Geophysical Research: Atmospheres, 2013, 118(16) : 8881-8896.

[81] Sun R H, Chen A L, Chen L D, Lü Y H. Cooling effects of wetlands in an urban region: the case of Beijing. Ecological Indicators, 2012, 20: 5764.

［82］朱春阳, 李树华, 纪鹏, 任斌斌, 李晓艳. 城市带状绿地宽度与温湿效益的关系. 生态学报, 2011, 31(2): 383-394.

[83] Hathway E A, Sharples S. The interaction of rivers and urban form in mitigating the Urban Heat Island effect: a UK case study. Building and Environment, 2012, 58: 14-22.

[84］纪鹏, 朱春阳, 高玉福, 李树华. 河流廊道绿带宽度对温湿效益的影响. 中国园林, 2012, 28(5): 109-112.

[85] 高玉福, 荣立苹, 李树华. 2 种外部环境对城市带状绿地温湿效益的影响比较. 西北林学院学报, 2018, 33(1) : 262-268.

[86] 李东海, 艾涁, 黎夏. 基于遥感和 GIS 的城市水体缓解热岛效应的研究——以东莞市为例. 热带地理, 2008, 28(5): 414-418.

[87］朱春阳，李树华，纪鹏. 城市带状绿地结构类型与温湿效应的关系. 应用生态学报, 2011, 22(5): 1255-1260.

[88] 佟华, 刘辉志, 李延明, 桑建国, 胡非. 北京夏季城市热岛现状及楔形绿地规划对缓解城市热岛的作用. 应用气象学报, 2005, 16(3)： 357-366.

[89］秦耀民, 刘康, 王永军. 西安城市绿地生态功能研究. 生态学杂志, 2006, 25(2): 135-139.

[90］李辉, 赵卫智, 古润泽, 李延明, 陈自新, 张新献. 居住区不同类型绿地释氧固碳及降温增湿作用. 环境科学, 1999, 20(6): 41-44.

[91] 高吉喜, 宋婷, 张彪, 韩永伟, 高馨婷, 冯朝阳. 北京城市绿地群落结构对降温增湿功能的影响. 资源科学, 2016, 38(6): 1028-1038.

[92] 萄银鼎, 韩学孟, 武小刚, 郝兴宇, 王娟, 梁锋, 梁娟, 王志红. 城市绿地空间结构对绿地生态场的影响. 生态学报, 2006, 26(10)： 3339-3346.

[93] 唐泽, 任志彬, 郑海峰, 何兴元. 城市森林群落结构特征的降温效应. 应用生态学报, 2017, 28(9) : 2823-2830.

[94] Gillner S, Vogt J, Tharang A, Dettmann S, Roloff A. Role of street trees in mitigating effects of heat and drought at highly sealed urban sites. Landscape and Urban Planning, 2015, 143: 33-42.

[95]杨学军, 孙振元, 韩蕾, 巨关升, 徐旭, 彭镇华. 五叶地锦在立体绿化中的降温增湿作用. 城市环境与城市生态, 2007, 20(6): 1-4.

[96] Butler C, Orians C M. Sedum cools soil and can improve neighboring plant performance during water deficit on a green roof. Ecological Engineering, 2011, 37(11): 1796-1803.

[97] 姜慧乐, 尹莉娜, 韩龙, 王宝, 陈广绪. 基于群落结构的杭州市公共建筑物立体绿化温湿效应研究. 湖北农业科学, 2013，52(6)： 1359-1365.

[98 ] Lee H, Mayer H, Chen L. Contribution of trees and grasslands to the mitigation of human heat stress in a residential district of Freiburg, Southwest 
Germany. Landscape and Urban Planning, 2016, 148: 37-50.

[99］廖容, 崔洁, 卓春丽, 高素萍. 成都市 32 种立体绿化植物降温增湿效应比较研究. 江苏农业科学, 2012, 40(6) : 178-181.

[100] 王晓娟, 孔繁花, 尹海伟, 徐海龙, 李俊生, 蒲英霞. 高温天气植被蒸腾与遮荫降温效应的变化特征. 生态学报, 2018, 38(12)： 4234-4244.

[101] Sodoudi S, Zhang H W, Chi X L, Muller F, Li H D. The influence of spatial configuration of green areas on microclimate and thermal comfort. Urban Forestry \& Urban Greening, 2018, 34: 85-96.

[102] Leuzinger S, Vogt R, Körner C. Tree surface temperature in an urban environment. Agricultural and Forest Meteorology, 2010, 150(1): 56-62.

[103] Rahman M A, Moser A, Gold A, Rötzer T, Pauleit S. Vertical air temperature gradients under the shade of two contrasting urban tree species during different types of summer days. Science of the Total Environment, 2018, 633: 100-111.

[104] 梁影严, 李晓晖, 肖荣波. 城市通风廊道规划与控制方法研究以《广州市白云新城北部延伸区控制性详细规划》为例. 风景园林, 2014, (5) : 92-96.

[105] Akbari H, Rose L S, Taha H. Analyzing the land cover of an urban environment using high-resolution orthophotos. Landscape and Urban Planning, 2003, 63(1): 1-14.

[106] 张玲, 李小娟, 周德民, 张翼然. 基于 Meta 分析的中国湖沼湿地生态系统服务价值转移研究. 生态学报, 2015, 35(16): 5507-5517.

[107] DerSimonian R, Laird N. Meta-Analysis in clinical trials. Controlled Clinical Trials, 1986, 7(3) : 177-188.

[108] 李海峰, 李永树, 卢正, 刘雪婷, 彭文甫. 绿地景观热环境效应的遥感研究. 测绘科学, 2018, 43(1): 66-72.

[109］梁保平, 马艺芳, 李晖. 桂林市典型园林绿地与水体的降温效应研究. 生态环境学报, 2015, 24(2): 278- 285.

[110] 王帅帅, 陈颖彪, 千庆兰, 谢锦鹏. 城市公园对城市热岛的影响及三维分析一一以州市主城区为例. 生态环境学报, 2014, 23(11)： 1792-1798.

[111] 周东颖, 张丽娟, 张利, 范怀欣, 刘栋. 城市景观公园对城市热岛调控效应分析一一以哈尔滨市为例. 地域研究与开发, 2011, 30(3): 73- 78 .

[112］贾琦, 运迎霞, 尹泽凯. 高密度城区公园降温效应与模拟预测研究—— 以津中心城区为例. 重庆大学学报, 2016, 39(2): 44-50.

[113] Bowler D E, Buyung-Ali L, Knight T M, Pullin A S. Urban greening to cool towns and cities: a systematic review of the empirical evidence. Landscape and Urban Planning, 2010, 97(3): 147-155.

[114] Völker S, Baumeister H, Classen T, Hornberg C, Kistemann T. Evidence for the temperature-mitigating capacity of urban blue space-a health geographic perspective. Erdkunde, 2013, 67(4) : 355-371.

[115] 雷江丽, 刘涛, 吴艳艳, 庄雪影, 谢良生. 深圳城市绿地空间结构对绿地降温效应的影响. 西北林学院学报, 2011, 26(4): 218-223.

[116］岳文泽, 刘学. 基于城市控制性详细规划的热岛效应评价. 应用生态学报, 2016, 27(11): 3631-3640.

[117] Stone B, Norman J M. Land use planning and surface heat island formation: a parcel-based radiation flux approach. Atmospheric Environment, 2006, 40(19): 3561-3573.

[118] Tan C L, Wong N Y, Tan P Y, Jusuf S K, Chiam Z Q. Impact of plant evapotranspiration rate and shrub albedo on temperature reduction in the tropical outdoor environment. Building and Environment, 2015, 94: 206-217.

[119] Razzaghmanesh M, Beecham S, Salemi T. The role of green roofs in mitigating Urban Heat Island effects in the metropolitan area of Adelaide, South Australia. Urban Forestry \& Urban Greening, 2016, 15: 89-102. 